\title{
La política exterior rusa pos Guerra Fría. ¿Caso paradigmático de revisionismo?
}

\author{
Sebastien Adins*
}

\section{Resumen}

Casi de modo unánime, discursos y documentos oficiales y, a la par, un gran número de textos académicos en Occidente tildan a Rusia como una potencia revisionista ${ }^{1}$. Sobre todo, a partir de la toma de Crimea y Sebastopol por parte de Moscú y el inicio del conflicto en el Donbás en el año 2014, se le considera al Estado eurasiático como un spoiler de la política internacional, en búsqueda del debilitamiento de los valores, las reglas e instituciones del denominado «Orden Internacional Liberal». El presente artículo se propone problematizar esta afirmación al postular que la categoría del revisionismo no constituye una proyección internacional unidimensional, ni tampoco objetiva. Por otro lado, siguiendo a Murray (2019), el revisionismo, además de emerger al interior de un Estado, también se construye a través de las interacciones sociales con otros Estados, como efecto de su pugna por el reconocimiento. Luego de una revisión de la literatura sobre dicho concepto y la ubicación de la teoría de Murray en ella, el presente artículo indaga en los motivos y las estrategias de Rusia en el orden pos Guerra Fría, así como las capacidades que sustentan su política exterior. Bajo esta luz, se evaluará el grado de revisionismo en la proyección internacional rusa de los últimos ańos.

Palabras clave: Rusia, revisionismo, política exterior rusa, potencias emergentes.

\footnotetext{
* Magíster en Relaciones Internacionales por Ghent University - Bélgica y doctor en Ciencia Política por la Pontificia Universidad Católica del Perú (PUCP).

(iD) https://orcid.org/0000-0002-7029-3369

1 Véase, por ejemplo, Allison (2017), Krastev (3 de marzo de 2014) y The White House (2017).
} 
Russian foreign policy post Cold War. Paradigmatic case of revisionism?

\section{Abstract}

Almost unanimously, official speeches and documents and, at the same time, a large number of academic texts in the West brand Russia as a "revisionist" power. Especially since the annexation of Crimea and Sevastopol by Moscow and the start of the Donbas conflict in 2014, the Eurasian state has been considered as a "spoiler" of international politics, supposedly in search of the weakening of the values, rules and institutions of the so-called "Liberal International Order". This article aims to problematize this statement by arguing that the category of revisionism does not constitute a one-dimensional international state behaviour, or an objective one. On the other hand, following Murray (2019), revisionism, in addition to its domestic roots, is built through social interactions with other countries, as part of a state's struggle for recognition. After a review of the literature on this concept and the position of Murray's theory, this article analyses the motives and strategies of Russia in the post-Cold War international order, as well as the capabilities that support its foreign policy. In this light, it will assess the "degree" of revisionism in Russia's international relations of recent years.

Keywords: Russia, revisionism, Russian Foreign Policy, rising powers.

\section{El concepto «revisionismo» en las relaciones internacionales}

El término «revisionismo», con un significado propio de la disciplina de las relaciones internacionales, aparece durante la primera mitad del siglo XX, en el contexto de - o en alusión a - la entonces transición de poder e irrupción de las potencias del Eje. Como tal, no debería sorprender que, en medio de la actual transición de poder, con el declive del Gran Occidente, el término ha realizado un comeback, tanto en la academia como en los discursos oficiales. Es común entre los primeros estudios sobre la materia bajo una perspectiva realista, el énfasis en la ocurrencia de guerras hegemónicas —o, más en general, el cambio en el sistema internacional—, así como la categorización dicotómica presente en estos. Respecto a esto último, si bien en la actualidad se suele distinguir entre las potencias statu quo (o conservadoras) y las «revisionistas», las denominaciones han variado. Así, por ejemplo, Carr (1939) distinguiría entre países satisfechos (o haves) e insatisfechos (have-nots), mientras que Morgenthau (1948) y Kissinger (1966) prefirieron usar las expresiones «imperialistas» $\mathrm{y}$ «revolucionarios» en referencia al segundo grupo.

Una de las teorías más influyentes sobre el papel sistémico de los Estados revisionistas fue la «teoría de transición de poder» de Organski, presentada por primera vez en 1958. Según este autor, el sistema internacional se caracterizaba por ser jerárquico (más que anárquico) y constituido por dos grupos de Estados: los satisfechos, liderados por la potencia dominante y generalmente provisionados de mayores capacidades; 
y los insatisfechos, mayormente ubicados en los estratos más bajos de la pirámide internacional. En cuanto a la potencia dominante —el hegemón-, esta moviliza sus capacidades económicas y militares superiores para establecer las reglas de juego del orden internacional, proveer determinados bienes públicos, asignar estatus e influir en la política doméstica de los Estados subordinados. Históricamente, según Organski, la probabilidad de una guerra sistémica habría aumentado considerablemente en el caso de una distribución igual de capacidades políticas, económicas y militares entre el Estado dominante declinante y un Estado retador emergente e insatisfecho con el orden internacional forjado por el dominante. En este caso, casi de modo espontáneo, los Estados satisfechos le respaldarían al primero, mientras que el retador tendría el apoyo de una coalición entre los insatisfechos. El resultado final, no obstante, siempre dependería del poder potencial, la velocidad de emergencia y el grado de insatisfacción del retador, la flexibilidad del hegemón y el nivel de hostilidad entre ambas potencias, entre otras variables.

A su vez, en el clásico War and Change in World Politics, Gilpin (1981) postularía que la inestabilidad internacional $-\mathrm{y}$ con ella, la probabilidad de una guerra sistémica- se debía a las diferencias de crecimiento entre los Estados, que gradualmente erosionan la base de la gobernanza internacional. De este modo, con una redistribución del poder disminuirían los costos para buscar cambios en el statu quo por parte de la(s) potencia(s) emergente(s), mientras que el Estado dominante trataría de contrarrestar este desafío a través de un cambio de su política, en búsqueda de una restauración del equilibrio en el sistema. Si esta política lograra acomodar al emergente, volvería la estabilidad; de lo contrario se acumularían las tensiones, haciendo casi inevitable la guerra. La exigencia de cambiar la delimitación de las zonas de influencia o las reglas que sustentan el sistema internacional constituyeron, para Gilpin, las expresiones más frecuentes del revisionismo de una potencia emergente.

Es constante en estas visiones sistémicas, que la potencia dominante fuera considerada, casi por definición, como el defensor del statu quo, mientras que la potencia emergente sería el origen de la inestabilidad internacional, movida por sus intenciones revisionistas. Por otro lado, no siempre estas perspectivas consensuaron respecto al significado del revisionismo. Mientras que algunos autores (como Morgenthau) definen al Estado revisionista como aquel que busca, meramente, maximizar su poder, otros también los asocian con la defensa de ciertos valores divergentes a los predominantes del statu quo. Desde esta última perspectiva, Wolfer (1962) menciona diversos motivos detrás de una proyección revisionista:

The aim may be more 'power as an end in itself' or domination over other peoples or territorial expansion; but it may also represent a quest for the return of lost territory, or the redress of legitimate grievances, such as termination of unjust discriminations, 
the emancipation from foreign control or imposition on others of an ideology or way of life. (pp. 91-92)

Recientemente, han surgido diversas reacciones frente a las visiones tradicionales del revisionismo. Algunos autores discrepan sobre el carácter inherentemente conservador de la potencia hegemónica $-\mathrm{y}$ su contraparte: el supuesto revisionismo de los emergentes - En este grupo, Schweller (2015) postula que parece ilógico que las potencias emergentes que lograron crecer más que el promedio de Estados bajo el orden existente, invertan cuantiosos recursos para reemplazar al statu-quo con un nuevo orden, cuyo futuro es incierto y cuyos costos tendrían que asumir. Además, recuerda que, de acuerdo con la teoría prospectiva, un actor en el dominio de las ganancias suele ser más averso al riesgo, que aquel que enfrenta pérdidas. Por ello, el autor sustenta que son los hegemones los mejores candidatos para actuar como potencias revisionistas, más aún en la ausencia de mayores contrapesos externos. En esa línea, la regime change policy, las intervenciones denominadas humanitarias, así como el abandono del multilateralismo por parte de Estados Unidos en el marco de la doctrina Wolfowitz (2001-2009) sustentarían esta afirmación. Así también, las políticas MAGA y America First de Donald Trump claramente encajan con el «revisionismo de la potencia dominante» ${ }^{2}$. Desde otro ángulo, en su libro The Origins of Major War, Copeland (2000) concluye que las guerras masivas han sido mayormente provocadas por Estados militarmente dominantes, pero que temen un declive significativo. A su vez, las potencias emergentes, al encontrarse en proceso de ascenso, suelen evitar mayores conflictos, considerando que postergarlos permite acumular mayores recursos de poder.

Una segunda crítica a las visiones tradicionales concierne a la lógica dicotómica entre Estados revisionistas, en un polo, y los defensores del statu quo, en el otro. Incluso el propio Schweller (1994), en un artículo muy influyente para su época, parte de un continuum, basado en el costo que un Estado estaría dispuesto a pagar para modificar (en el caso de los revisionistas) o conservar el orden internacional. Al respecto, Sergunin (2020), entre otros, proponen una tercera categoría de Estados llamados reformistas o pluralistas, que defienden ciertos cambios al statu quo, pero dentro de los márgenes del orden internacional. Precisamente una mayoría de los poderes emergentes en la actualidad pertenecería a esta categoría.

Un tercer grupo de autores cuestiona la supuesta naturaleza unidimensional del revisionismo. Davidson (2006) distingue entre cinco terrenos donde puede variar el grado de (in)satisfacción de un Estado: la distribución territorial, el estatus, el

\footnotetext{
2 Cabe anotar que, en ambos casos, autores mainstream como Ikenberry (2012, 2017) llegaron a reconocer la proyección revisionista de Estados Unidos.
} 
acceso a mercados, la ideología y, finalmente, el campo del derecho internacional y las instituciones internacionales. A su vez, Cooley, Nexon y Ward (2019) proponen una clasificación de cuatro tipos de Estados, según su ubicación frente a dos dimensiones: el nivel de respaldo al balance de poder, por un lado, y su apoyo a los otros aspectos del orden internacional (sus valores o instituciones, por ejemplo). De esta manera, además de los conservadores existen Estados reformistas (satisfechos con el balance de poder, mas no con el resto del orden), posicionalistas (solo insatisfechos con el balance de poder) y revolucionarios (no conformes en ambas dimensiones).

También en desacuerdo con los enfoques unidimensionales sobre el revisionismo, Pisciotta (2020) postula que el revisionismo puede involucrar cambios en el terreno de las normas, los regímenes, cuestiones territoriales o la jerarquía de poder, propia del orden, entre los cuales algunos dominios de revisión serían más peligrosos que otros para la estabilidad internacional. Así también, Schweller (2015) contrarresta la supuesta equivalencia entre revisionismo e inestabilidad sistémica al presentar cuatro condiciones que determinan si el revisionismo de un Estado representa una amenaza para las potencias establecidas y/o el orden internacional existente: (1) el alcance del revisionismo (objetivos limitados o ilimitados); (2) la propensión de riesgo del actor revisionista; (3) la naturaleza de los objetivos revisionistas (por ejemplo, la defensa de cambios en las normas internacionales, la distribución territorial o la jerarquía de prestigio) y (4) los medios para promover estos objetivos (pacíficos o violentos). Finalmente, Pisciotta (2020) agrega a la naturaleza de objetivos y el tipo de medios, una tercera vinculada al nivel de acción, que puede ser regional o más bien global.

Más allá de la intensidad y la naturaleza del revisionismo, cabe indagar algunos de los motivos que explicarían una proyección revisionista. Tal como se adelantó líneas arriba, para los estructuralistas, la insatisfacción y deseo de modificar el statu quo entre algunos Estados resulta principalmente de algún cambio (emergencia o declive) en sus capacidades relativas. Mientras tanto, otros autores rescatan la importancia de la opinión pública nacional, las presiones ejercidas por grupos de interés y sus respectivas ideas. Davidson (2006), por ejemplo, reconoce, además de las presiones y oportunidades externas, el rol que juegan ciertos grupos de presión o coaliciones nacionalistas, como una fuente del revisionismo.

En cambio, Ward (2013) asocia el revisionismo con aquellos Estados que sufren de una «incongruencia de estatus». Para este autor, el estatus de un Estado refiere a la posición que ocupa dentro de una jerarquía públicamente reconocida y colectivamente comprendida. Al igual que el estatus social, dichas jerarquías se caracterizan por ser intersubjetivas —así, los status markers dependen mucho del contexto- y supeditadas al reconocimiento de los «otros significativos», los cuales son principalmente actores de un estatus alto. Por ello, un aspirante a gran potencia no solo debe poseer 
los atributos que marcan su estatus como gran potencia, sino también ser reconocida como tal por las otras grandes potencias. Además, si bien el estatus puede traer ciertas ventajas tangibles - en el caso de Estados: contar con una zona de influencia, participar en clubes de élites o poseer la capacidad de que otros Estados ajusten sus políticas a la propia, etc.—, también puede constituir un fin en sí mismo, basado en el respeto y el prestigio que conlleva. En cuanto a la inconsistencia del estatus, para Ward (2013) implica "[...] a situation in which an individual, group, or state is not recognized by other actors as having achieved the level of status that the individual, group or state believes it deserves or to which it aspires» (p. 613), lo que suele causar un comportamiento agresivo. Finalmente, de dicha incongruencia pueden resultar dos opciones: o renunciar a un estatus mayor u por una estrategia revisionista optar — según el mismo autor este sería un escenario más probable-.

También vinculado con la pugna por el reconocimiento se presenta la visión de Murray (2019) sobre el revisionismo — tal como lo indica el título de su libro-. Para esta autora, el revisionismo constituye una construcción social que no solo emerge desde adentro de los Estados. Su punto de partida concierne al hecho de que la política exterior de un Estado no solo busca asegurar intereses materiales, sino también las identidades de este — por ejemplo: la identidad de gran potencia-, como actor en la sociedad internacional, lo que requiere reconocimiento por parte de las potencias establecidas (los «otros significativos» de este caso). De la misma manera como ocurre con las personas, los Estados no pueden establecer identidades por su cuenta: una identidad recién se vuelve significativa a través de las interacciones con los demás Estados. Ahora bien, cuando la potencia emergente logra obtener este reconocimiento, «[...] its identity is brought into existence, its status as a political actor is secured and as a result, it is able to act in the international sphere in ways consistent with the role of major power [...]» (Murray, 2019, p. 7). Además, dicho reconocimiento conlleva la neutralización del dilema de seguridad con las potencias establecidas y facilita el ascenso pacífico del emergente.

Sin embargo, este proceso implica una gran incertidumbre para el Estado en cuestión — siempre existe el riesgo de no obtener este reconocimiento tan necesario-, más aún en un contexto de anarquía sistémica. Una forma de tratar de superar esta inseguridad social, según Murray (2019), consiste en realizar prácticas de reconocimiento, es decir gestos asociados con la identidad de una gran potencia, no exentos de riesgo y que pueden ser agrupados en tres grupos. Primero, existe la posibilidad de hablar con la voz de una gran potencia para así obtener respeto, al asumir responsabilidades de gestión, reclamar un asiento en la mesa o hasta instigar crisis internacionales para llamar la atención de las grandes potencias. Una segunda práctica refiere a la adquisición de poder militar «ejemplar» (por ejemplo, portaviones o armas nucleares), 
la organización de eventos deportivos de alto nivel o el desarrollo de un programa espacial $^{3}$. Finalmente, cabe la opción de delimitar una zona de influencia en la cual reclama el derecho —el droit de regard - de moldear sus políticas internas. En esta etapa puede surgir el denominado dilema de inseguridad social, que emerge cuando las acciones tomadas por una potencia para asegurar o defender su identidad, pueden afectar, y hasta poner en peligro, la seguridad física de otros Estados. En efecto, es muy probable que las acciones descritas sean interpretadas como ilegítimas o amenazantes por las potencias establecidas, por lo que, en vez de reconocer a la aspirante a gran potencia, pasan a tratarla como un actor inferior y no integrante del club de grandes potencias. Dicha experiencia a su vez es interpretada por el aspirante como una falta de respeto y esta, al no aceptar su posición inferior a los poderes establecidos, intensifica su campaña de prácticas de reconocimiento ${ }^{4}$. Al final, este comportamiento, a la vez más confrontacional y riesgoso, será securitizado y contenido por las grandes potencias y, con ello, se inicia la construcción de la potencia aspirante como un actor revisionista. Según Murray, una de las condiciones críticas para que los poderes establecidos lleguen a legitimar las acciones del aspirante (y, como tal, lo reconozcan con su respectiva identidad), concierne al vínculo positivo de identidad. Dicho de otro modo: es más probable ver el reconocimiento de un actor emergente que coincida con las grandes potencias a nivel de modelo político, idioma, su raza, etc.

En resumen, el concepto de revisionismo sigue siendo contestado, tanto a nivel académico como político. Sin embargo, al menos en los debates contemporáneos de relaciones internacionales, se han superado aquellas perspectivas dicotómicas que dividen al sistema internacional, meramente, entre actores defensores del statu quo y revisionistas. Asimismo, se requiere diferenciar entre revisionismos que buscan una redistribución de bienes (como cambios territoriales o a nivel de una zona de influencia) y aquellos normativos que promueven algún cambio en las normas o reglas del orden internacional o en las portadoras de estas (las organizaciones internacionales). Finalmente, en cuanto al origen de comportamientos revisionistas, está claro que tanto (f)actores domésticos como presiones externas pueden encontrarse en su base. Por otro lado, el revisionismo constituye una construcción social que emerge con base en la búsqueda de reconocimiento por parte de algunos Estados y la recepción de este pedido por parte de las potencias establecidas, en particular.

\footnotetext{
3 En este sentido, Murray (2019) compara este grupo de prácticas con el consumo conspicuo de las clases sociales emergentes.

4 Aunque no lo menciona Murray, Malinova (2014) describe esta reacción del «no reconocido» como ressentiment, una referencia a un estado psicológico resultante de sentimientos suprimidos de envidia y odio hacia el objeto de imitación, percibido como superior. Por ello, ambos sujetos se caracterizan por ser a la vez comparables y desiguales.
} 


\section{Rusia en el actual orden internacional}

\subsection{Los antecedentes: la política exterior rusa pos Guerra Fría}

\subsubsection{Los años noventa}

Durante los primeros cuatro años de su independencia, Rusia seguiría una política marcadamente euro-atlantista bajo el liderazgo del entonces ministro de Relaciones Exteriores, Andréi Kozyrev. Sobre todo, la relación con Estados Unidos recibiría una gran prioridad en aquel periodo, algo que se reflejaba en la suscripción de alrededor de cien acuerdos entre ambas potencias en este periodo (1992-1996). Con este acercamiento, Moscú buscaba posicionarse como un socio estratégico indispensable —un equal partner - de Occidente. Además, esperaba recibir su respaldo económico a fin de aliviar las secuelas dramáticas de la terapia de shock, implementada por Yeltsin con la asesoría del Fondo Monetario Internacional y expertos occidentales. Por otro lado, la orientación prooccidental propia de la política exterior de Kozyrev complementó las reformas domésticas en el país, con la liberalización de su economía y lo que parecía ser una democratización del sistema político. En el marco de esta política, Rusia también se acercó a varias organizaciones y foros, liderados por Occidente, tales como el G7, la OTAN, el GATT/OMC, el Consejo Europeo y la Comunidad/Unión Europea ${ }^{5}$. En paralelo, se presenció un retroceso en las relaciones entre la otrora superpotencia y países del Sur y tampoco se otorgó gran prioridad a los vínculos con las nuevas repúblicas del espacio postsoviético ${ }^{6}$.

Sin embargo, esta nueva proyección internacional no traería particularmente un impacto positivo para el país. En medio de una de las crisis económicas y sociales más brutales de la historia, Occidente no solo brilló por su indiferencia, sino que trataba a Moscú como la potencia derrotada de la Guerra Fría, prefiriendo postergar la adhesión rusa tanto a la «Comunidad Atlántica» como a la «casa común europea»" Tal como lo demuestra, por ejemplo, el episodio de bombardeos de la OTAN contra

\footnotetext{
5 Como tal, Rusia ingresó al Fondo Monetario Internacional y el Banco Mundial en 1992, al GATT al ańo siguiente, cofundó en 1995, la Organización para la Seguridad y la Cooperación en Europa (OSCE) —con base en la Conferencia de Helsinki y la Carta de París-e ingresó al Consejo de Europa en 1996.

6 En cambio, sí se enviaron tropas rusas para el mantenimiento de la paz en Tayikistán, Transnistria, Abjasia y Osetia del Sur.

7 En vez de otorgarle la plena membresía a la OTAN, se prefirió establecer en 1994 una «Asociación por la Paz» (PfP, por sus siglas en inglés), a fin de facilitar la cooperación entre dicha alianza militar y los ex integrantes del Pacto de Varsovia. A su vez, con el concepto de "casa común europea», Gorbachov hizo un llamado a favor del establecimiento de una arquitectura de seguridad paneuropea, en sus palabras "desde Lisboa hasta Vladivostok» que, como lo había propuesto Charles de Gaulle décadas antes (con «l'Europe de l'Atlantique à l'Oural»), debía superar las diferencias ideológicas entre sus integrantes.
} 
objetivos serbios en Bosnia y Herzegovina en $1994^{8}$, Rusia podía recibir un trato como junior partner ${ }^{2}$. En claro contraste, las élites y población rusas compartían una perspectiva muy diferente a la predominante en Washington. Si bien su país estaba pasando por una crisis interna transitoria, no consideraban a la URSS/Rusia como el perdedor de la Guerra Fría, sino como el actor que había promovido el fin - pacífico - de dicha contienda y protagonizado una transformación del sistema internacional, a partir del «nuevo pensamiento político» de Gorbachov. Desde esta visión, Rusia, en vez de experimentar una disminución de su estatus, merecía un reconocimiento por este rol histórico, con un lugar privilegiado en el orden pos Guerra Fría. Las siguientes palabras, expresadas por el historiador Karaganov, sintetizan dicho enfoque, además de articular la cuestión de estatus internacional con la política doméstica del país:

Russia was treated as a defeated nation, yet Russians do not consider themselves losers. Generally speaking, over the past five hundred years Russians have developed a habit of never losing large wars. Russia was faced with a velvet-gloved version of the Versailles policy [...]. The West insisted that Russia should know its restricted and reduced place in world politics. By pushing Russia into the periphery of global politics, the West fueled a kind of Weimar syndrom in Russia, a great nation whose dignity and interests were trampled underfoot. (2018)

De esta manera, pocos ańos después de haber inaugurado una nueva política exterior liberal y euroatlantista, los sentimientos de humillación y resentimiento empezaron a predominar entre la población rusa, profundamente inmersa en una crisis de identidad, dando lugar al éxito electoral del Partido Comunista y los ultranacionalistas en las elecciones parlamentarias de 1995. Este acontecimiento claramente constituyó un hito para la edificación de un nuevo consenso en la política exterior rusa, una línea que - con ciertos vaivenes - se ha mantenido hasta la actualidad y que tuvo como arquitecto a Yevgeny Primakov, el siguiente canciller ruso en el periodo comprendido entre 1996 y 1998.

En síntesis, la denominada «doctrina Primakov» constituye una lectura realista de la política internacional, que considera a Rusia como una histórica gran potencia. En palabras del propio ministro pronunciadas en 1997: «Russia always was, is and will

\footnotetext{
8 Pese a que Rusia pertenecía al Grupo de Contacto sobre la ex Yugoslavia, Occidente insistió en llevar a cabo estos bombardeos contra la «Republika Srpska», siendo los serbios un histórico aliado de Rusia en los Balcanes.

9 Vale recordar que el propio Kozyrev (1994), en un artículo escrito como ministro de Relaciones Exteriores en 1994 para Foreign Affairs, alertaría sobre la existencia de ciertos intereses de los complejos industriales militares y facciones políticas que iban en contra de una asociación estratégica entre Estados Unidos y Rusia: «The traditional American Sovietologists harp on the difficulties and unpredictability of Russia's internal processes, which do not fit the usual Western criteria and stereotypes. Some analysts cannot accept the idea of a strong Russia, whether it be imperial or democratic. They propose that the West either take a wait-and-see approach or develop a new containment strategy» (p. 60).
} 
be a great power $[\ldots]$, así que "[...] her foreign policy should correspond to that status» (citado en Smith, 2014). De ello deriva que la nación debía optar por una política plenamente autónoma y basada en sus intereses nacionales, para así figurar como uno de los principales polos de poder en un orden "policéntrico», sentado en la cooperación y el respeto por el derecho internacional. En su calidad de gran potencia, a su vez, reclamaba para sí mismo una zona de influencia — «una esfera de intereses privilegiados» en la jerga oficial rusa — que coincide con el «extranjero cercano» del espacio postsoviético.

Desde esta perspectiva, guiada por Primakov, a partir de 1996, Rusia empezó a proyectar una clásica política de balanceo suave (soft balancing) frente a las iniciativas hegemónicas de Estados Unidos. Así, sin adoptar una política hostil hacia la entonces superpotencia americana, la meta consistió en buscar una asociación selectiva, conforme a sus intereses, por ejemplo, en su vecindario, y en condiciones de igualdad. Por otro lado, se estimaba que un nuevo orden multipolar no solo traería una democratización del sistema internacional, sino también, al igual que durante el siglo XIX, mayor estabilidad, algo esencial para materializar la recuperación económica y, en general, la consolidación doméstica de Rusia como potencia. Clave en este esfuerzo fue la proyección de una política exterior más proactiva y «multivector», que no solo miraría hacia Occidente, sino también a las exrepúblicas exsoviéticas y al resto del mundo.

En esta línea, bajo iniciativa de Primakov, se inauguró una política de alineamiento con China e India con base en el triángulo estratégico (o RIC, predecesor de los BRICS). Asimismo, se intensificaron las relaciones bilaterales con algunos países clave de Medio Oriente, Europa, América Latina y África, que compartían con Moscú el deseo de vivir en un orden poshegemónico. En cuanto al «extranjero cercano», Rusia sentó las bases de un regionalismo explícitamente «eurasiático» e impulsó una política más activa en la región, al considerar su importancia en el terreno estratégico, económico y por la presencia de unos 25 millones de rusos en dicho vecindario (véase más adelante). Más alejado de la ex URSS, Moscú ofreció su mediación en las crisis de Iraq y Kósovo y priorizó su participación en organizaciones multilaterales, sin peso dominante de Occidente, tales como el Consejo de Seguridad de la Organización de Naciones Unidas (ONU), el Consejo de Europa o los Cinco de Shanghái (actualmente, Organización de Cooperación de Shanghái). Sobre todo, la ONU obtuvo una gran atención por la política exterior rusa, al considerarla un mecanismo esencial en el mantenimiento de un balance de poder y la cooperación intergubernamental, y como defensora de la soberanía estatal. 
Si bien durante la segunda administración de Yeltsin, Rusia fue admitida al G7+1 ${ }^{10}$, dos acontecimientos acaecidos en 1999 marcarían la desconfianza rusa hacia las intenciones de Occidente. Primero, se formalizó la ampliación de la OTAN con tres países ex integrantes del Pacto de Varsovia ${ }^{11}$. Este proceso contradijo claramente la promesa realizada en 1990 por el entonces secretario de Estado, James Baker, hacia Mijaíl Gorbachov de no mover las fronteras de la alianza «ni una sola pulgada» ${ }^{12}$. Tampoco consideró la preocupación expresada por decenas de expertos y diplomáticos en Occidente sobre las posibles secuelas de esta expansión. En este sentido, tal vez la reacción más memorable fue la de George Kennan, ícono de la diplomacia estadounidense, quien criticó la acción por ser innecesaria y la fuente de futuras tensiones con Moscú. A inicios de 1997, anotaría las siguientes palabras:

[...] expanding NATO would be the most fateful error of American policy in the entire post-cold-war era. Such a decision may be expected to inflame the nationalistic, anti-Western and militaristic tendencies in Russian opinion; to have an adverse effect on the development of Russian democracy; to restore the atmosphere of the Cold War to East-West relations, and to impel Russian foreign policy in directions decidedly not to our liking. (Citado en Owen, 2017, p. 117)

En el mismo año, la misma OTAN volvería a usar la fuerza en los Balcanes, esta vez en respaldo de los separatistas de Kosovo, con una campaña de bombardeos masivos sobre diversas ciudades de la entonces confederación Serbia-Montenegro y sin contar con algún mandato del Consejo de Seguridad de la ONU. Si bien esta vez el Kremlin actuó inesperadamente con la toma del aeropuerto de Pristina (por delante de las tropas de la OTAN), al igual que en 1994, la crisis demostró la desconsideración occidental por los intereses históricos de Rusia en la zona, así como por la soberanía estatal.

\subsubsection{La politica exterior rusa en el siglo XXI}

Aunque la política exterior de Yeltsin pasó por dos grandes momentos — de alineamiento (Kozyrev) y balanceo suave (Primakov) hacia Occidente- en el periodo que va de 2000 a 2021 es posible distinguir tres etapas ${ }^{13}$. En una primera, entre los ańos 2000 y 2007, Putin claramente impulsó un reacercamiento con Occidente.

\footnotetext{
${ }^{10}$ Inicialmente, empero, solo pudo participar en las reuniones de carácter político (y no las principales entre los ministros de Finanzas), por ello se denominó G7+1 en aquellos años. Recién en el año 2002 nacería el G8 (hasta la expulsión de Rusia en 2014).

11 La República Checa, Hungría y Polonia.

12 Véase el memorándum de la conversación entre Baker, Shevardnadze y Gorbachov el 9 de febrero 1990 en Moscú: https://nsarchive.gwu.edu/briefing-book/russia-programs/2017-12-12/ nato-expansion-what-gorbachev-heard-western-leaders-early

13 Aquí consideramos tres grandes etapas, con la segunda de 2007 a 2012, caracterizada por un carácter transitorio. Otros autores como Feklyunina (2019) y Sakwa (2020) solo distinguen entre dos periodos: de 2000 a 2012 denominado «compitiendo con Occidente» por la primera autora y «nuevo realismo» por el segundo; y, de 2012 para adelante, llamado «desafiando Occidente» por Feklyunina y «neo-revisionismo» según Sakwa.
} 
El gesto más visible de esta nueva línea se dio con el respaldo ruso en la «Guerra contra el Terror» de G.W. Bush. En este marco, Rusia decidió abrir su espacio aéreo para aviones estadounidenses rumbo a Afganistán, intercambiar inteligencia sobre las redes jihadistas en Asia Central y ofrecer el uso de bases ex soviéticas en Uzbekistán y Kirguistán. Asimismo, Moscú impulsó la idea de una "Gran Europa», no solo como un espacio económico único, sino además como un área de convergencia estratégica, en el espíritu de Gorbachov (Trenin, 2015). Con base en la iniciativa, se acordó en 2005, elaborar un paquete de rutas para establecer cuatro «espacios comunes» entre Bruselas y Moscú, aunque sin avances transcendentales durante los ańos siguientes. Hasta se volvió a mencionar, como en la era Kozyrev, de una posible incorporación rusa a la OTAN. La relación personal positiva entre Vladimir Putin y Gerhard Schroeder, Jacques Chirac e, incluso, George W. Bush, contribuyó con esta dinámica positiva. En el corto plazo, la nueva estrategia pareció dar frutos: Estados Unidos pasó a reconocer a Rusia como economía de mercado, permitió su ingreso como miembro pleno del nuevo G8 y se creó el Consejo OTAN-Rusia ${ }^{14}$.

No obstante, pronto, el unilateralismo de la administración neoconservadora estadounidense creó nuevas fricciones. Así, en 2002, Estados Unidos anunció su decisión de retirarse del histórico Tratado ABM de 1972, para luego estrenar su proyecto de un escudo antimisiles, a fin de protegerse contra los rogue states y el terrorismo internacional. Al año siguiente, nuevamente desafiando al Consejo de Seguridad, Washington dio luz verde para la invasión de $\operatorname{Iraq}^{16}$ y se daría la primera de tres «revoluciones de color»; protestas populares en contra de líderes amigables hacia Moscú estalladas en Georgia (2003), Ucrania (2004) y Kirguistán (2005). Según la lectura rusa, estas movilizaciones fueron instigadas desde Occidente bajo la misma lógica de "promoción» de la democracia», aplicada con anterioridad en Serbia e Iraq. Dicha versión pareció quedar confirmada cuando los recién instalados mandatarios de Georgia y Ucrania stante pede solicitaron su adhesión a la OTAN y la Unión Europea. A su vez, para el año 2004, se concretó la quinta ampliación de la OTAN con siete nuevos miembros, entre ellos, las tres repúblicas exsoviéticas del Báltico. En paralelo, cada vez más, Estados Unidos expresaría su «preocupación» por el estado de

\footnotetext{
${ }^{14}$ En este espíritu, en una declaración conjunta de Bush y Putin de mayo de 2002 se postulaba que ambos Estados "[...] will observe in good faith their obligations under international law, including the UN Charter, provisions and principles contained in the Helsinki Final Act and the OSCE Charter for European Security. In the framework of the Nato-Russia Council, Nato member states and Russia will work as equal partners in areas of common interest. They aim to stand together against common threats and risks to their security» (The Guardian, 24 de mayo de 2002).

${ }^{15}$ En este periodo, además, el Gobierno estadounidense dejó de criticar las operaciones rusas en Chechenia, aceptando así su vinculación con la Guerra contra el Terror, tal como lo defendió Moscú.

${ }^{16}$ Pese a que Rusia se opondría a esta invasión al tener intereses económicos en el país árabe y en defensa del principio de soberanía, fueron Francia y Alemania los que lideraron la oposición en el Consejo de Seguridad contra la política estadounidense.
} 
la democracia y los derechos humanos en Rusia, sus políticas energéticas y su política en el espacio postsoviético, calificada como «imperialista» (Shakleina, 2013).

Esta serie de políticas, recibidas como «humillaciones» en Rusia, parecían confirmar la idea de una renovada política occidental de contención en su contra, una narrativa ya muy popular en aquellos ańos entre los denominados siloviki - representantes del complejo industrial militar y la inteligencia- y círculos nacionalistas en Rusia. El rechazo de Estados Unidos a la propuesta de Putin para construir un escudo antimisiles conjunto contribuyó aún más con esta lectura (Larson y Shevchenko, 2014). Por otro lado, respaldado por la expansión económica y la estabilidad social lograda en esta etapa, paulatinamente, Rusia recurrió a un discurso más asertivo en el escenario internacional y fortaleció sus aspiraciones como gran potencia, una tendencia que se hizo más manifiesta en el siguiente periodo. En palabras del propio Putin: Rusia finalmente se levantaba de sus rodillas.

El segundo periodo, comprendido entre los años 2007 y 2012, constituyó una especie de bisagra en la política exterior reciente de Rusia, al exhibir una combinación de enfrentamientos entre el país y Occidente, con muestras de voluntad de cooperación expresadas por ambas partes. Dicha etapa inicia simbólicamente con el famoso discurso dado por Putin en la Conferencia de Seguridad de Múnich, donde alertó sobre la inestabilidad que traería el uso de la fuerza sin mandato del Consejo de Seguridad y, en general, las aspiraciones de supremacía global por parte de la entonces potencia hegemónica. Asimismo, expresó explícitamente la preocupación rusa frente a las políticas occidentales al afirmar:

I think it is obvious that NATO expansion does not have any relation with the modernisation of the Alliance itself or with the ensuring security in Europe. On the contrary, it represents a serious provocation that reduces the level of mutual trust. And we have the right to ask: against whom is the expansion intended? And what happened to the assurances our western partners made after the dissolution of the Warsaw Pact? Where are those declarations today? (Putin, 2007 ${ }^{17}$ )

$\mathrm{Al}$ ańo siguiente, se llegaría a un enfriamiento completo de las relaciones con la tajante oposición rusa al reconocimiento occidental de Kósovo (en marcha desde febrero de 2008) ${ }^{18}$ y la guerra ruso-georgiana de agosto, que terminó con el reconocimiento ruso de Abjasia y Osetia del Sur, a lo que se opuso Occidente. Pocos meses antes, Putin incluso había viajado a Bucarest para declarar en una cumbre de

\footnotetext{
${ }^{17} \mathrm{https} / / /$ www.youtube.com/watch? $\mathrm{v}=\mathrm{hQ} 58 \mathrm{Yv} 6 \mathrm{kP} 448 \mathrm{t}=174 \mathrm{~s}$

18 A partir de febrero de 2008, de modo masivo y, principalmente, Estados con una orientación prooccidental empezaron a reconocer a Kósovo como Estado. Sin embargo, aún hay excepciones como los cinco integrantes de la UE que se oponen a dicho reconocimiento. En total, al momento de escribir este artículo, 98 de los 193 integrantes de la Asamblea General de la ONU reconocen a Kósovo.
} 
la OTAN que la adhesión de Georgia y Ucrania a la alianza sería considerada como una "amenaza directa» y una «línea roja» para Moscú ${ }^{19}$. Por último, la Asociación Oriental ${ }^{20}$, impulsada desde Polonia a fin de profundizar los lazos de la Unión Europa con seis repúblicas exsoviéticas en el terreno comercial, económico y político, volvió a ser interpretada por Moscú como un avance geopolítico del bloque en su zona de influencia. Todo ello, en combinación con la insatisfacción rusa sobre su exclusión de la arquitectura de seguridad europea —en 2009, la propuesta de Medvedev sobre un tratado de seguridad europea volvería a ser rechazada ${ }^{21}$ — contribuyó con el fortalecimiento de una narrativa interna de «fortaleza asediada» (Feklyunina, 2019). Por otro lado, al igual que en el caso de Kósovo, Rusia intensificaría su estrategia de «toma y daca $»^{22}$ hacia varias iniciativas occidentales. Así, por ejemplo, en el año 2007 anunció el proyecto Southstream, un gasoducto entre Rusia, los Balcanes e Italia, que fue visto como «rival» de la iniciativa occidental Nabucco, que precisamente buscó disminuir la dependencia energética de Europa con un gasoducto desde Iraq, Azerbaiyán y Turkmenistán. Desde la misma lógica, se estableció el medio Russia Today que procuró romper, junto con otros medios no occidentales, el histórico monopolio de Occidente en la difusión global de noticias.

No obstante, tanto la llegada al poder del nuevo presidente ruso, Dmitry Medvedev (2008-2012), considerado más liberal que Putin, como de Barack Obama — con su política reset hacia Moscú-, ayudaron a mejorar las relaciones entre Rusia y Occidente en los años siguientes. En este espíritu, Washington y Moscú acordaron establecer una Comisión Presidencial Bilateral para concretar su cooperación en cuestiones como el desarme nuclear — materializado con el START III, suscrito en 2010—, la guerra de Afganistán — por ejemplo, con el restablecimiento del corredor aéreo a través de Rusia—, el programa nuclear iraní y en el espacio. Además, en el año 2012, con respaldo occidental, Rusia lograría ingresar a la Organización Mundial del

\footnotetext{
${ }^{19}$ Si bien Alemania y Francia se opusieron a la admisión de Georgia y Ucrania como nuevos miembros de la OTAN al considerar la postura rusa, la declaración final de la cumbre sí mencionó que, eventualmente, ingresarían a la alianza militar (https://www.nato.int/cps/en/natolive/official_texts_8443.htm).

${ }^{20}$ La Asociación Oriental refiere a una iniciativa de la Unión Europea que, como parte de su política europea de vecindad, busca profundizar los lazos en materia comercial-económica, conectividad, movilidad de personas y a nivel político entre el bloque y seis repúblicas exsoviéticas: las tres transcaucásicas, además de Bielorrusia, Moldavia y Ucrania. Si bien nació como una iniciativa de Polonia, considerada la potencia regional emergente de Europa Oriental pero también uno de los miembros más críticos hacia Moscú de la Unión Europea, fue presentada conjuntamente con Suecia durante un Consejo de ministros de Relaciones Exteriores en Bruselas en 2008.

${ }^{21}$ Dicho proyecto se basó en el concepto de "Occidente ampliado», que considera a Rusia como el tercer centro, además de Estados Unidos y la Unión Europea, del sistema occidental de Estados. Con la propuesta de este tratado, Rusia buscó superar la ineficacia y divergencias entre los organismos existentes en materia de seguridad (OTAN, UE, OSCE, OTSC) para así prevenir conflictos en Europa (Shakleina, 2013).

${ }^{22}$ Con el término "toma y daca» (tit for tat), se entiende la estrategia de represalia de un determinado Estado contra la política de un contrincante. Generalmente, iniciativas soviéticas como el Plan Molotov, el COMECON y el Pacto de Varsovia son consideradas ejemplos de esta política.
} 
Comercio, luego de diecinueve años de negociaciones, e iniciar su proceso de adhesión a la OCDE (Zonova y Reinhardt, 2014). También con la Unión Europea, se presenció un reacercamiento a través de la "Asociación para la Modernización», a fin de profundizar los lazos económicos entre Moscú y Bruselas, y a través de diversos acuerdos bilaterales con sus Estados miembros. A su vez, los flujos comerciales entre ambas partes pasaron por un auge durante aquel periodo. Cabe mencionar que, sobre todo a partir de la Gran Recesión de 2008, Rusia empezaría a perfilarse internacionalmente como una potencia «emergente». En esta calidad, convocó la primera cumbre de los BRIC en Ekaterimburgo para el año 2009, luego de haber participado en la primera reunión de alto nivel del G20, un año antes. Por otro lado, continuó avanzando con la institucionalización del regionalismo eurasiático con el establecimiento de una unión aduanera en 2010 entre Rusia, Bielorrusia y Kazajstán, como punto de partida de la futura Unión Económica Eurasiática (UEEa).

La tercera etapa en la política exterior rusa reciente arranca con las protestas masivas en Rusia a fines de 2011, contra los resultados oficiales de las elecciones parlamentarias y tendría como auge la crisis ucraniana, seguida por la toma de Crimea y Sebastopol. En cuanto a las movilizaciones populares — que duraron más de un año y se desarrollaron con la Primavera Árabe aún fresca en la memoria-, estas fueron interpretadas por el Kremlin como otro intento occidental de instigar una revolución de colores, dirigida esta vez contra el propio Putin, que asumió nuevamente la presidencia desde mayo de 2012. Fue en este particular contexto que el discurso del mandatario ruso empezaría a evolucionar desde un perfil pragmático-tecnocrático, dominante durante sus primeras gestiones, a una retórica abiertamente conservadora y nacionalista. En este sentido, las referencias a la defensa de los valores tradicionales cristianos o de los derechos para los "compatriotas en el extranjero" ${ }^{23}$ — la diáspora rusa residente en el «extranjero cercano»— estuvieron cada vez más presentes en el discurso oficial del Kremlin. Así también, al asociar la oposición con Occidente, se aprobó una legislación más rígida frente a las ONG financiadas desde el exterior (principalmente, Estados Unidos) y se recortó el derecho de protesta, exacerbando la tendencia autoritaria en la política rusa. La promulgación de la Ley Magnitsky ${ }^{24}$, otra

\footnotetext{
$23 \mathrm{Al}$ respecto, se suele referir a la «Doctrina Karaganov», en referencia a la publicación de un artículo presentado en 1992 por Sergey Karaganov, que hizo un llamado a favor de la defensa de los derechos de los aproximadamente 25 millones de rusos y/o rusófonos que habían quedado residiendo en repúblicas soviéticas, fuera de Rusia. Cabe anotar que dicho artículo fue una reacción a las políticas discriminadoras hacia las minorías rusas en varios de estos países, principalmente del Báltico.

${ }^{24}$ En referencia al auditor ruso, Serguei Magnitsky, esta ley estadounidense inicialmente buscaba sancionar a funcionarios rusos involucrados en casos de corrupción. A partir del 2016, empero, autoriza al gobierno de Estados Unidos sancionar a funcionarios extranjeros alrededor de todo el mundo, implicados en violaciones de los derechos humanos. En respuesta a esta ley, la Duma estatal rusa emitió una prohibición sobre la adopción de niños rusos por parte de familias estadounidenses.
} 
negativa estadounidense ante la insistencia rusa de construir un escudo antimisiles en conjunto y una nueva aplicación de la regime change policy en Libia ${ }^{25}$, solo contribuyeron con este nuevo ciclo negativo de las relaciones.

No obstante, fue la crisis ucraniana iniciada en noviembre de 2013, el hito determinante de esta tercera etapa. Al igual que en 2004, la república exsoviética - y segundo país más extenso de Europa — volvió a ser el objeto de una pugna geopolítica entre Moscú y Bruselas/Washington, cuando el entonces presidente Yanukovich, pese a su inclinación prorrusa e interés en el regionalismo eurasiático, empezó a negociar un acuerdo de asociación y un tratado de libre comercio (el DCFTA) con la Unión Europea $^{26}$. Al considerar el rol histórico de Ucrania como Estado-colchón para Rusia y el hecho de que una expansión en la influencia del bloque europeo pronto conllevaría una adhesión de la república a la OTAN, el gobierno ruso empezó a ejercer presión sobre Kiev para que paralizara este proceso, hasta que finalmente cedió ${ }^{27}$. Así, cuando Yanukovich, en última instancia, se rehusó a suscribir ambos acuerdos durante una cumbre en Vilna, iniciaron las protestas masivas, conocidas como Euromaidán, en contra del gobierno ucraniano. Inicialmente, estas movilizaciones fueron protagonizadas por una multitud de jóvenes, la clase media y partidos políticos liberales, que no solo expresaron su identidad europeísta, sino también su descontento con el autoritarismo y la corrupción que caracterizaba al entonces gobierno ucraniano. No obstante, con el paso del tiempo, el movimiento quedaría cooptado por elementos minoritarios violentos y extremistas; entre otros, del movimiento fascista Pravy Sektor, que abiertamente rindió culto a Stepan Bandera, líder nacionalista ucraniano y colaborador durante la ocupación nazi. Como tal, pese a que la oposición oficial había negociado con Yanukovich una transición pacífica hasta la celebración de nuevas elecciones, dichas agrupaciones lograron destituir al presidente e instalar un nuevo gobierno de facto, con base en una coalición de dos partidos prooccidentales y Svoboda, de ultraderecha y conocida por sus posturas antirrusas. Con este gobierno se inaugura una política de ucranianización, lo que implicó, por ejemplo, la eliminación de monu-

\footnotetext{
${ }^{25}$ Cabe anotar que Rusia, al igual que China, India, Brasil y Alemania, se abstuvo en la votación sobre la Resolución 1973 del Consejo de Seguridad, por la que se exigió un cese al fuego inmediato en el conflicto libio, a fin de proteger a los civiles e instaurar una zona de exclusión aérea. No obstante, con base en esta resolución aprobada dos días después, la OTAN iniciaría su intervención militar en Libia, que terminó, luego de siete meses, con la caída del régimen de Gadafi.

${ }^{26} \mathrm{Si}$ bien, según las encuestas, una mayoría de la población de la capital y las regiones occidentales de Ucrania se mostró a favor de este acercamiento hacia Bruselas, dicha política no contó con mayor respaldo entre los habitantes del Sur y el Este, cultural e históricamente más orientados hacia Moscú. Por otro lado, las cadenas productivas establecidas durante la era soviética hicieron que Rusia siguiera siendo, de lejos, el mayor socio comercial de Ucrania: en el ańo 2012 abarcó un 24\% de las exportaciones y un 30,7\% de las importaciones (OEC 2021). En este sentido, la suscripción de un TLC con la UE generaría un gran impacto en los flujos comerciales entre ambos vecinos.

${ }^{27}$ Además de presionar al gobierno ucraniano para que no firmara el acuerdo, Moscú ofreció la suma de 15000 millones de dólares en ayuda económica (Mearsheimer, 2014).
} 
mentos exsoviéticos, la polémica derogación de una ley que garantizaba el uso del ruso (hablado por casi 30\% de la población ${ }^{28}$ ) como idioma regional y la ilegalización del Partido de las Regiones (prorruso). El respaldo explícito por parte de Occidente a este gobierno de facto $^{29}$ — tildado de fascista por Moscú — solo aumentaría la presión al Kremlin para que revirtiera esta «humillación» producida en medio de las Olimpiadas de Invierno organizadas por la propia Rusia.

La administración de Putin optaría por dos respuestas. Por un lado, con el temor de perder su histórica base naval de Sebastopol, dentro de la semana de instalado el nuevo gobierno ucraniano, envió tropas especiales rusas para tomar control de la infraestructura estratégica de Crimea y la ciudad de Sebastopol ${ }^{30}$, para seguidamente alentar la organización de un referéndum sobre el estatus político de ambos territorios. Aunque no contó con alguna observación institucional de Occidente, en el referéndum ganaría claramente la opción de integración a la Federación Rusa, que sirvió como base para la suscripción, dos días después, de un tratado de accesión ${ }^{31}$. De esta manera, para sorpresa de Occidente, Putin — con un respaldo masivo de la población rusa - había demostrado estar dispuesto a usar la fuerza a fin de contrarrestar cualquier nuevo avance geopolítico de Occidente en una república considerada crucial para la seguridad de Rusia. A la vez, empero, el mismo hecho - una clara violación del derecho internacional - traería un deterioro de la imagen internacional del Estado, considerado un defensor de la soberanía e integridad territorial ${ }^{32}$. Asimismo, la espiral de sanciones económicas y personales recíprocas, la expulsión de Rusia desde el G8 y el congelamiento de su proceso de incorporación a la OCDE y, en general, de su cooperación con Bruselas/Washington, securitizaron por completo las

\footnotetext{
${ }^{28}$ Según el (último) censo de 2001 en Ucrania, 29,6\% de la población hablaba ruso y un 17,3\% se consideró étnicamente ruso, aunque con grandes diferencias regionales: Sebastopol $(90,6 \%)$, Crimea $(77 \%)$, Donetsk $(74,9 \%)$ y Luhansk (68,8\%) contaban con una mayoría rusófona (http://2001.ukrcensus.gov.ua/eng/results/).

${ }^{29}$ Con anterioridad ya se presenció la participación de varias personalidades occidentales durante las protestas contra Yanukovich, entre otras el senador estadounidense John McCain, la entonces secretaría de Estado - asistente para Asuntos Europeos y Eurasiáticos de Estados Unidos, Victoria Nuland y el líder de la fracción liberal en el Parlamento Europeo, Guy Verhofstadt.

${ }^{30}$ Entre las razones que explican la rápida toma de poder en la península, se menciona la lealtad prorrusa entre una mayoría de la población (y su temor ante el nuevo gobierno ucraniano), la presencia de tropas rusas en la base baval de Sebastopol desde la desintegración de la URSS, la deserción masiva de militares ucranianos (entre ellos el propio jefe de Armada de Ucrania) y la «sugerencia» de Estados Unidos de evitar cualquier enfrentamiento directo con Rusia en la Crimea, para contrarrestar cualquier justificación de una intervención de mayor escala en el resto de Ucrania (Allison, 2017).

${ }^{31}$ Con una participación del $83,1 \%$ del electorado, un 96,77\% votaría a favor de la adhesión de Crimea a Rusia, mientras que en Sebastopol se obtuvo un $95,6 \%$ de votos a favor con una participación de $89,5 \%$. Cabe anotar que según las diversas encuestas del PNUD realizadas entre 2009 y 2011, solo un 9 a 15\% de los encuestados (principalmente tártaros y ucranianos no rusófonos) se mostró opuesto a una salida de Ucrania.

32 Como tal, ninguno de los demás Estados exsoviéticos, ni siquiera países aliados de Rusia como Armenia, Bielorrusia y Kazajstán, reconocieron la incorporación de Crimea/Sebastopol a la Federación Rusa.
} 
relaciones con Occidente. Para algunos, en 2014 había iniciado la segunda Guerra Fría (Sakwa, 2020a).

En segundo lugar, Moscú buscaría debilitar y socavar la autoridad del nuevo gobierno ucraniano, eliminando el subsidio sobre la venta de gas al vecino y a través de la activación de una guerra híbrida en respaldo de los separatistas prorrusos en la región del Donbás. Luego de siete años —y 14000 víctimas mortales en ambos bandos- el conflicto en el este ucraniano sigue siendo un tema de suma criticidad para la seguridad paneuropea. Por otro lado, la intervención rusa también constituye una especie de «garantía» en manos de Moscú, para evitar el ingreso de Kiev a la OTAN: tradicionalmente, la alianza militar no permite la adhesión de un Estado envuelto en un conflicto activo con un vecino. Por cierto, el conflicto no solo contribuiría con una alienación completa entre ambos pueblos hermanos, sino también — paradójicamente- con una mayor cohesión entre ucranianos, una nación históricamente dividida.

Pese a que, con anterioridad a la crisis ucraniana, Rusia y China ya habían logrado profundizar sus vínculos en diversos terrenos, a partir de 2014, Moscú aceleraría esta política de «Pivote hacia el Este» (Sakwa, 2020b) ${ }^{33}$. En este marco, se produciría una armonización de sus posturas en el escenario multilateral, un incremento de la cooperación militar y en materia de seguridad, así como una intensificación de los lazos económicos y energéticos. Inclusive, algunos autores han mencionado la existencia de una especie de división de trabajo entre Moscú y Beijing, con el primero siendo más activo en el terreno de seguridad y el segundo en la gobernanza económica, financiera y hasta medioambiental (Kaczmarski, 2020). Empero, los enormes avances de la República Popular China en el campo tecnológico, el gran alcance de su Iniciativa del Cinturón y la Ruta (BRI) y el propio perfil del intercambio comercial bilateral, contribuyeron a generar alertas en Rusia sobre la creciente asimetría de las relaciones, a favor de China ${ }^{34}$. Por otro lado, con el establecimiento formal de la UEEa en el año 2015, la profundidad del regionalismo eurasiático —el otro pilar del «Pivote hacia el Este»— avanzaría considerablemente al constituirse un mercado común entre sus integrantes y con un diseño organizacional muy similar a la UE (aunque mayormente intergubernamental) ${ }^{35}$.

\footnotetext{
$33 \mathrm{Al}$ respecto, Trenin (2015) distingue entre tres «pivotes»: hacia sí mismo (a través de una política orientada a «recuperar la soberanía»), hacia Eurasia (con la UEEa) y hacia el Asia (con una expansión de la inversión pública en Siberia y el Extremo Este, así como la profundización de los lazos con China).

${ }^{34}$ Una parte considerable de los envíos rusos a China consiste en recursos naturales (principalmente petróleo), mientras que las exportaciones chinas hacia el mercado ruso suelen ser (semi)manufacturas. Una vez operativos los tres enormes gasoductos entre Rusia y China se acentuará el perfil asimétrico de sus relaciones comerciales.

35 Si bien con la creación de la UEEa, Rusia buscaría incrementar el peso colectivo de la Eurasia postsoviética en el sistema internacional e impulsar la interconectividad y comercio intrarregional (actualmente aún por debajo del $10 \%)$, también aspiró a presentarla como un segundo pilar de la Gran Europa, siendo el primero la Unión Europea
} 
Desde el año 2014 en adelante, las divergencias estratégicas entre Rusia y Occidente solo se multiplicarían. Con el inicio de las operaciones militares rusas en Siria, en respaldo al régimen de Bashar Al-Assad, y el desarrollo de relaciones pragmáticas con cada uno de los protagonistas del Medio Oriente (Irán, Arabia Saudita, Israel, los Emiratos Árabes Unidos e Egipto), Moscú crecientemente se convertiría en un verdadero game changer de dicha región, en detrimento de Occidente. Pese a las múltiples incompatibilidades geopolíticas con Turquía, miembro de la OTAN y cada vez más distante de Occidente, también se logró construir una relación sumamente estrecha. A su vez, la llegada al poder de Donald Trump, en medio de los rumores sobre una supuesta interferencia rusa en el proceso electoral de 2016 (el denominado Russiagate), no generó avance alguno en las relaciones bilaterales, más allá de las aparentes muestras de aprecio mutuo. Así lo demostraron la imposición de nuevas sanciones desde Washington (por ejemplo, por el caso Skripal), las expulsiones recíprocas de diplomáticos o las constantes acusaciones dirigidas hacia Rusia sobre desinformación y hacking. Pasados los cuatro primeros meses de la administración Biden, la caracterización de Putin como asesino por parte del presidente estadounidense, la cuestión Navalny y una escalada de tensiones en Ucrania, reflejan que el escenario de una mejora en las relaciones entre ambas potencias parece haberse alejado. Por otro lado, tanto la insistencia alemana de seguir con la construcción del gasoducto Northstream II, los llamados de Emmanuel Macron a favor de una reintegración de Rusia al G8 ${ }^{36}$, y la oposición de Berlín y París contra una expansión de la OTAN hacia nuevas repúblicas exsoviéticas demuestran que Occidente no ha tenido una postura monolítica hacia Moscú.

\subsection{Capacidades de la Rusia actual: ¿el caso de una potencia híbrida?}

Look at the state of Russia now. They're in enormous decline. By any definition, these guys are on a toboggan run. The question is: when the run ends.

Joe Biden, enero 2018

Del marco teórico de este artículo se puede concluir que una mayoría de autores atribuye el revisionismo a las potencias emergentes, aunque otros (como Schweller) lo asocian con los declinantes. Por ello, antes de determinar el grado de revisionismo en la política exterior rusa, se precisará qué tipo de potencia es Rusia en el orden

\footnotetext{
(Sakwa, 2020c). Por otro lado, pese a la coordinación oficial entre el bloque y la BRI está claro que la UEEa sirve como un regionalismo defensivo liderado por Moscú ante la creciente penetración geoeconómica de China en la región.

${ }^{36}$ En general, llama la atención cómo París y Moscú de facto se mantienen alineados sobre una serie de cuestiones internacionales, entre otras, la guerra civil en Libia, el conflicto de Nagorno Karabaj, la disputa del Egeo y la cuestión nuclear iraní.
} 
internacional actual, para luego resumir sus principales objetivos y estrategias de política internacional.

A nivel de capacidades duras, la Federación Rusa claramente presenta algunas grandes ventajas como potencia. Antes que nada, cuenta con el territorio más grande del mundo, ubicado en dos continentes, aunque sin mayores barreras naturales que lo protejan de agresiones externas (con la excepción del Cáucaso) o puertos importantes ubicados en aguas templadas. Así también, alberga enormes reservas de recursos naturales, principalmente energéticos, minerales e hídricos. En la actualidad, de lejos es el principal exportador de gas natural en el mundo, así como el segundo de crudo — su principal producto de exportación-, luego de Arabia Saudita. Este perfil de superpotencia energética, evidentemente, confiere a Rusia un importante peso político hacia los países dependientes de estos recursos, empero a la vez obstaculiza el proceso de modernización y diversificación de la economía rusa. A nivel militar, constituye, junto con Estados Unidos, una de las dos principales potencias nucleares, figura en el segundo puesto a nivel de exportación de armamento e, igualmente, ocupa un segundo lugar en el Global Fire Index del año $2021^{37}$. No obstante, a nivel de gasto militar, durante el último lustro, se ha ubicado entre el tercer y quinto rango, muy por debajo de Estados Unidos y China, y con niveles similares a la India y Arabia Saudita.

Por otro lado, la población rusa actual se encuentra en el noveno puesto del mundo, con aproximadamente 142 millones de habitantes y una tendencia de contracción demográfica que podría llevarla al puesto 14 para el año 2050 $0^{38}$. A nivel de indicadores sociales, Rusia ocupa el puesto 52 en el índice de desarrollo humano (IDH), detrás de países como Chile y Argentina, debido a la reducida esperanza de vida (72,6 años), en comparación con países de un nivel de desarrollo similar. En materia cultural, constituye una civilización única, al ser claramente occidental a nivel lingüístico y religioso, aunque simultáneamente, este país es considerado como el «otro» desde la perspectiva del propio Occidente.

En términos económicos, después del estancamiento que caracterizó a la economía soviética durante los años ochenta y la caída libre de la Rusia posindependencia con un estimado de $44 \%$ del PBI en solo cinco años ${ }^{39}$-, la economía atravesaría una expansión importante durante el periodo comprendido entre 1998 y 2014. A raíz de los bajos precios de los hidrocarburos y a las sanciones impuestas por Occidente a Rusia a partir de 2014, siguió una recesión de tres años. Recién en 2017, la economía rusa volvió a crecer, aunque a tasas bajas entre 1,34\% (2019) y 2,54\% (2018), hasta

\footnotetext{
37 https://www.globalfirepower.com/

38 (https://population.un.org/wpp/Graphs

39 Véase Rosefielde (2001).
} 
el inicio de la pandemia COVID-19 (véase Gráfico 1). Así, en términos absolutos, el PBI nominal ruso ocupa un sexto puesto, medido en términos de paridad de poder adquisitivo y podría bien mantenerse en esta posición, según una proyección de $\mathrm{PwC}$ al año $2050^{40}$. Como es sabido, pese a haber heredado desde la era soviética, una gran capacidad industrial y know-how científico, el comercio internacional de Rusia depende, principalmente, de la exportación de recursos naturales. No obstante, también es importante anotar que, desde inicios del presente siglo, se ha logrado incrementar la competitividad económica, así como mantener una situación macroeconómica sostenible.

Gráfico 1. Tasas de crecimiento anuales del PIB ruso, 1990-2019

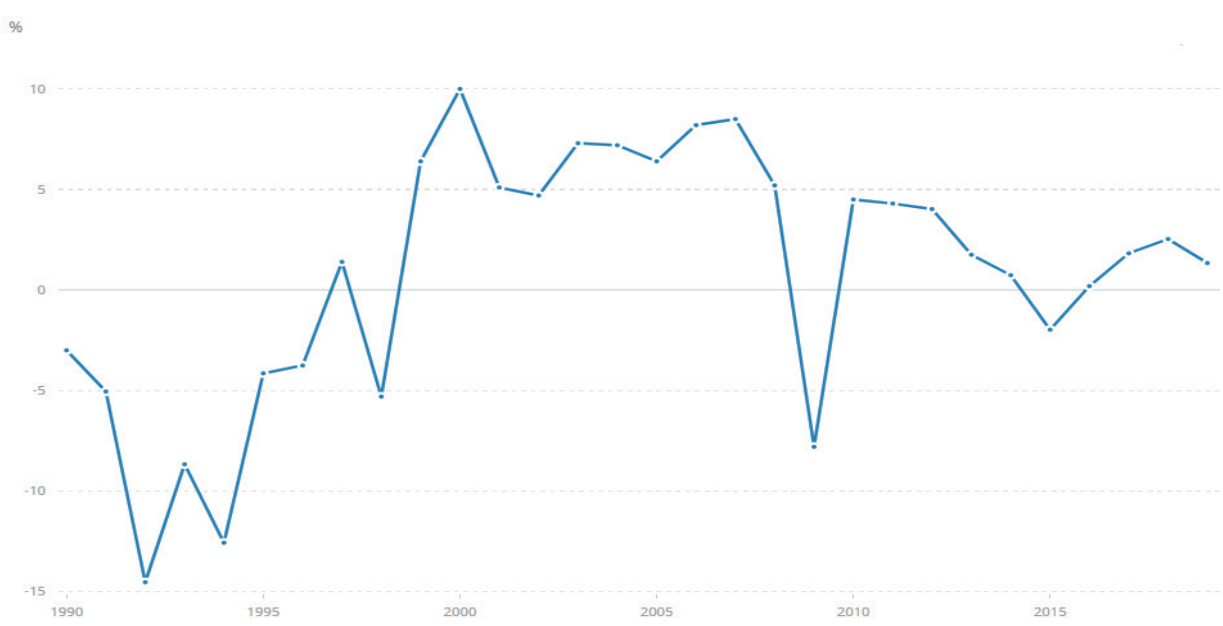

Fuente: Banco Mundial, 2021 11

Finalmente, en el terreno político, desde la llegada al poder de Vladimir Putin, Rusia cuenta con una administración estable y acompañada de una considerable aceptación popular a lo largo de los años ${ }^{42}$. Empero, aún está por verse si problemas estructurales como la corrupción, los estándares de vida de las mayorías o el propio carácter autoritario del sistema político pueden poner en peligro esta situación. En el plano externo, Rusia cuenta con una red diplomática extensa que la coloca en el quinto puesto del Índice de Diplomacia Global para el año $2019^{43}$. Luego de haber sido una

\footnotetext{
40 https:/www.pwc.com/gx/en/research-insights/economy/the-world-in-2050.html

41 https://datos.bancomundial.org/indicator/NY.GDP.MKTP.KD.ZG?locations=RU

42 Pese a sus veinte ańos en el poder, según el Centro Levada, la aprobación del presidente Putin en el periodo 20182021 se ha ubicado entre un 60 y $70 \%$ (https://www.levada.ru/en/ratings/

43 https://globaldiplomacyindex.lowyinstitute.org/
} 
gran potencia desde el siglo XVIII y una de las dos superpotencias durante la Guerra Fría, ha logrado acumular una gran experiencia en materia diplomática, con una relativa estabilidad en cuanto a sus objetivos, como se verá más adelante. Asimismo, considerada el Estado sucesor de la URSS, Rusia mantiene su asiento permanente en el Consejo de Seguridad y sigue jugando un rol vital en diversas agendas del multilateralismo pos Guerra Fría. Entre otras, en los campos, de la no proliferación nuclear y la reducción de las armas estratégicas, la lucha contra el crimen organizado y el extremismo islamista, la seguridad paneuropea, la energía, el espacio, la cuestión nuclear iraní, y las tensiones en la península coreana, Afganistán y el Medio Oriente.

Tal como se adelantó líneas arriba, desde la primera década del presente siglo, en un contexto de recuperación económica y consolidación doméstica, Rusia empezó a perfilarse como una "potencia emergente», cuya máxima expresión fue el establecimiento del foro BRIC. Además de la (re)emergencia económica que tuvo lugar hasta el año 2014, Moscú también comparte varios valores políticos con los poderes emergentes como, por ejemplo, la defensa de la soberanía estatal y, derivado de ella, el escepticismo frente a las políticas occidentales de promoción de la democracia y a los intervencionismos «humanitarios». Aunque menos proactivo en estas agendas, Moscú también defiende, al igual que las potencias emergentes, la necesidad de reformas en la gobernanza económica y comparte sus posturas en las áreas de gobernanza medioambiental y desarrollo (Parlar Dal y Erşen, 2020). Por otro lado, Rusia considera a las potencias emergentes como socios estratégicos para la construcción de un orden internacional no solo multipolar y plural (en los sentidos político y cultural), sino además poshegemónico. En este sentido, especialmente a través de su participación en los BRICS, el país ha logrado movilizar respaldo político a favor de algunas de sus posturas, mejorar su imagen, así como evitar su aislamiento internacional en medio de las tensiones que mantiene con Occidente (Sergunin, 2020).

Al mismo tiempo, empero, Rusia también podría ser considerada como una gran potencia tradicional por su trayectoria histórica y activismo internacional actual, sobre todo, en materia de seguridad internacional e incluso por sus raíces culturales cristianas. A su vez, también sus capacidades militares y nucleares, y su pertenencia a «clubes de élites» como el P5 del Consejo de Seguridad y, hasta 2014, el G8, lo acercan más a la categoría de las potencias establecidas. Por lo tanto, Rusia cuenta un perfil internacional híbrido, al combinar el comportamiento de una potencia tradicional en algunos terrenos, con los roles e incluso la identidad de una potencia emergente en otras áreas de la política internacional. Está claro que, tal como comenta Contessi (2017), estos dos roles no siempre se complementan: «Although Russia partly builds its strength on the broader emerging powers movement, it also needs to ensure it is not left out in the ongoing renegotiation of power. Therefore, the 
general frame of the responsible stakeholder approach preferred in Washington was bound to disappoint Moscow, for which the key phrase is instead 'equal partnership'» (p. 270). Como tal, si bien, oficialmente, Rusia respalda una reforma del Consejo de Seguridad, a través de una ampliación con nuevos integrantes permanentes, a la vez es consciente que esta medida de alguna manera podría «devaluar»su propia membresía del P5.

Cabe anotar que la idea predominante en Occidente sobre una "Rusia declinante» no se condice con las proyecciones de la economía global, tal como se mencionó líneas arriba. Asimismo, la "caída» demográfica, proyectada a inicios del siglo, no se materializó ${ }^{44} \mathrm{y}$, aunque parezca difícil, también podría ser mitigada en el futuro a través de políticas de fomento de la inmigración de rusos o rusófonos del «extranjero cercano» o de poblaciones provenientes de la Eurasia postsoviética. Por otro lado, con el cambio climático y la inauguración de la «Ruta Marítima del Norte» como nueva línea marítima de comunicación, se espera que el histórico aislamiento ruso a nivel de logística comercial se reduzca dramáticamente, con los efectos positivos que ello implicaría para su economía.

\subsection{Los objetivos y estrategias externas de Rusia}

To «decline to the level of a second class power [... and] become an Asiatic state [...] would be a major catastrophe for Russia». Aleksandr Izvol'sky, ministro de Relaciones Exteriores ruso, 1907

En cuanto a los principales objetivos de la actual política exterior rusa, de acuerdo con la Doctrina Primakov, se distinguen cuatro: (1) preservar la seguridad y defender la soberanía estatal; (2) obtener el reconocimiento como gran potencia; (3) contribuir con la consolidación de un orden internacional policéntrico y; (4) contar con droits de regard en la Eurasia postsoviética, como la esfera de influencia de Rusia.

En relación con la preservación de la seguridad nacional y la defensa de la soberanía e integridad territorial, estas constituyen históricas aspiraciones de Rusia. Incrustada en las llanuras eurasiáticas, sin protección natural alguna que pueda contener agresiones desde el Oeste (v.g. Napoleón y Hitler) o el Este (v.g. los mongoles), Moscú primero buscaría refugio en el expansionismo para, posteriormente, para el siglo XX,

\footnotetext{
44 A modo de ilustración, un estudio de la ONU realizado en el año 2000 proyectaba una caída de la población rusa de 146 a 134 millones para el año 2016 (https://www.un.org/en/development/desa/population/events/pdf/expert/2/ nikitina.pdf). En realidad, si bien se vio una reducción en el número de habitantes a 142,7 millones para el ańo 2008, luego tendió a aumentarse nuevamente y estancarse en unos 144 millones hasta la fecha.
} 
impulsar el establecimiento de Estados colchón en su flanco occidental, mitigando así la sensación de inseguridad. Tanto la creación del Pacto de Varsovia, como la neutralidad de países como Finlandia en tiempos de la Guerra Fría partieron de esta consideración. Desde este ángulo, los avances de la OTAN en el centro y este de Europa a lo largo de las últimas décadas volverían a contribuir con una percepción de inseguridad en Moscú. Sobre todo, la incorporación de las tres repúblicas del Báltico fue considerada una provocación al rodear completamente el exclave ruso de Kaliningrado, así como mover la frontera de la OTAN a tan solo 150 kilómetros de San Petersburgo, la segunda ciudad del país ${ }^{45}$. El académico estadounidense Mearsheimer (2014) anota al respecto, lo siguiente:

Washington may not like Moscow's position, but it should understand the logic behind it. This is Geopolitics 101: great powers are always sensitive to potential threats near their home territory. After all, the United States does not tolerate distant great powers deploying military forces anywhere in the Western Hemisphere, much less on its borders. Imagine the outrage in Washington if China built an impressive military alliance and tried to include Canada and Mexico in it. (p. 82)

Por otro lado, la primacía de la soberanía e independencia en la política exterior rusa no solo se rige por la defensa de los intereses nacionales, sino que también procura contrarrestar cualquier tipo de interferencia occidental en su política doméstica. Tanto el respaldo occidental a favor de la reelección de Yeltsin en 1996 y de candidaturas liberales — a partir de llegada de Putin al poder-, como su rol en las denominadas «Revoluciones de Colores», contribuyen con esta óptica defensiva. De ello también se deriva que el discurso internacional del Kremlin enfatice en la defensa de los principios westfalianos, tal como quedan plasmados, por ejemplo, en la Carta de Naciones Unidas. Desde la misma óptica, las políticas de promoción de la democracia y las constantes intervenciones de Occidente fuera de sus límites son tildadas de revisionistas y como la causa principal de inestabilidad del orden internacional pos Guerra Fría.

Un segundo objetivo de la política exterior rusa concierne a la búsqueda de reconocimiento como "gran potencia». Cabe subrayar que dicha categoría, atribuida a un pequeńo número de Estados en el sistema internacional, no solo se basa en la gran cantidad relativa de capacidades nacionales (principalmente, militares, económicas, políticas e ideacionales), la autonomía política y la voluntad para asumir una proyección global, sino también del reconocimiento por parte de las demás potencias. Por esta razón, al tratarse de un estatus, no constituye un concepto políticamente neutro, ni objetivo. De la misma manera como Estados Unidos o históricamente, Francia

45 La distancia entre el centro de San Petersburgo y Narva, la ciudad más oriental de Estonia es de 158 kilómetros. 
y Reino Unido, la idea de figurar como — y seguir siendo— gran potencia (velikoderzhavnost) constituye una parte esencial de la identidad internacional de Rusia, compartida por una gran mayoría de su élite política y de la misma sociedad ${ }^{46}$. Pese a su clara tendencia prooccidental, la siguiente cita del primer ministro de Relaciones Exteriores de Rusia sirve como ilustración al respecto:

The majority of Russian political forces wants a strong, independent and prosperous Russia. From this fundamental fact it follows that the only policy with any chance of success is one that recognizes the equal rights and mutual benefit of partnership for both Russia and the West, as well as the status and significance of Russia as a world power. Russian foreign policy inevitably has to be of an independent and assertive nature. If Russian democrats fail to achieve it, they will be swept away by a wave of aggressive nationalism. (Kozyrev, 1994, p. 61)

La referida identidad de "gran potencia», conformada a lo largo de los últimos trescientos años, mantiene una estrecha relación con la noción excepcionalista de «Camino Especial», en referencia a los diversos roles —o «misiones»— internacionales que Rusia ejecutó a lo largo de los siglos: desde figurar como defensor de los valores cristianos («Tercera Roma») y promotor del «paneslavismo», hasta ser líder, durante la era soviética, del proletariado internacional, así como constituir una civilización "puente» entre Occidente y Oriente (Kubyshkin y Sergunin, 2012; Tsygankov, 2012). No obstante, también es cierto que, salvo periodos excepcionales de radicalismo ideológico, la "razón de Estado» —es decir, la fortaleza y estabilidad del Estado- ha primado por encima del perfil ideológico en la proyección internacional del país (Robinson, 2020). Además de presentarse como una potencia única, con una misión a cumplir en el concierto de naciones, también su rol protagónico en la lucha contra las tropas de Napoleón y los nazis, y su papel positivo en el fin de la Guerra Fría, suelen ser citados como pilares de esta identidad. En esta línea, también son entendidas las palabras del actual ministro de Relaciones Exteriores, Serguei Lavrov: «i...] for 300 years Russia has already borne a good deal of the burden of sustaining the balance in European and world politics; when it abstained from this role... the result was unhealthy European politics» (Contessi, 2017, p. 273). Finalmente, al tomar nota de la importancia que la propia población rusa le atribuye al estatus internacional de su país, constituye un elemento importante para el grado de legitimidad política de la clase política y para la propia unidad de este enorme Estado.

\footnotetext{
${ }^{46}$ Según las encuestas del Centro Levada, en 2018, un 75\% de la población entrevistada consideraba a Rusia como una gran potencia/superpotencia, en contraste con el 31\% en 1999 (https://www.levada.ru/en/2019/01/25/ national-identity-and-pride). A su vez, en el mismo 2018, un 62\% consideraba a los rusos como un pueblo especial con un lugar propio en la historia mundial. Por otro lado, ante la pregunta "qué camino histórico» debía llevar el país, en 2015 un 55\% respondió con «un camino especial» y un 19\% con "regresar al camino donde se encontraba la URSS» (https://www.levada.ru/en/2015/05/20/the-historical-path/).
} 
Al respecto, el propio Putin sustentaría que «Russia can only survive and develop within the existing borders if it stays as a great power» (Tsygankov, 2012, p. 31). Tal como se desarrollará en la siguiente sección, generalmente, Occidente no considera a la Federación Rusa actual como una gran potencia, a diferencia del reconocimiento conferido en las Conferencias de Viena (1814-15) y Yalta (1945).

Tercero, Rusia busca contribuir con la consolidación de un orden internacional multipolar o en sus palabras, "policéntrico», en el cual Estados Unidos deje de jugar un rol hegemónico. Las élites rusas no niegan que Washington sigue figurando como la potencia más fuerte del mundo contemporáneo, pero sí cuestionan la idea de que sea un «líder global» reconocido e indisputado (Shakleina, 2013). En este sentido, la doctrina de la "coexistencia pacífica», desarrollada durante el siglo XX, aún sirve de modelo ${ }^{47}$. Por un lado, esta orientación puede ser considerada como el tradicional «balanceo» frente a la potencia dominante, al incluir a este nuevo orden otros polos de poder (emergentes), como China, India y Brasil, con un "carácter nacional» propio, es decir, con una versión propia del capitalismo o régimen político. Por otro lado, al defender el pluralismo, también en el sentido cultural, Moscú procura presentar una alternativa a la narrativa de un supuesto universalismo de valores (encarnado en el "Fin de la Historia»), y de una globalización unificadora y homogeneizadora. De la misma manera, se asume que solo un mundo multipolar puede garantizar la estabilidad que Rusia requiere para poder consolidarse internamente ${ }^{48}$. En términos del Ministerio de Relaciones Exteriores ruso: "The attempts made by western powers to maintain their positions in the world, including imposing their point of view on global processes and conducting a policy to contain alternative centers of power, leads to greater instability in international relations and growing turbulence on the global and regional levels» (MID, 2016, p. 3). Así, al igual que realistas occidentales como Henry Kissinger, se busca inspiración en la primera parte del siglo XIX (18151853), un periodo conocido por su estabilidad geopolítica alcanzada con base en el Concierto Europeo. Según esta lectura, la turbulencia que caracteriza al orden internacional actual podría ser mitigado a través de un «nuevo concierto» de grandes potencias (Karaganov, 2016).

También a nivel europeo, Rusia promueve la idea de un orden regional pluralista, tal como quedó plasmado en el Consejo Europeo e inicialmente, en la Organización

\footnotetext{
${ }^{47}$ La versión más conocida de "coexistencia pacífica» data del periodo de 1956 en adelante, cuando Jrushchov la propuso en relación con Estados Unidos, adelantando así la Détente pos 1962. Sin embargo, Lenin fue el primero en defender que el Estado socialista tenía que proyectar una coexistencia pacífica hacia los Estados con otros modelos sociales.

${ }^{48}$ La preferencia por la estabilidad en el sistema internacional se expresa en el último Concepto de Política Exterior de la Federación Rusa (2016) que menciona la palabra en 24 ocasiones.
} 
para la Seguridad y la Cooperación en Europa, siendo esta última, la institucionalización de la histórica Conferencia de Helsinki de 1973, convocada durante la «coexistencia pacífica» entre la URSS y Occidente. A esta Gran Europa también se refirió el discurso de Gorbachov sobre una "casa común europea" y, previamente, ante la visión gaullista de una «Europa desde el Atlántico hasta los Urales». Si bien la Unión Europea constituye, principalmente, un bloque económico, según Moscú, comparte con la OTAN la lógica de «expansión» del histórico Occidente, con sus respectivas formas de pensar y organizarse, sin considerar (e incluir) los propios intereses e identidades de Moscú, Kiev y Ankara ${ }^{49}$. Sobre ello, Sakwa (2017) afirma lo siguiente:

The West invited Russia to join an expanded Atlantic Community, but Russia sought to join a transformed West and a reconfigured Europe [...] [Russia] was offered associate membership of an existing enterprise (what I shall call the Historical West), but Russiass enduring aspiration was to become a founding member of Greater West. An analogous process was at work in Europe, where Russia was offered a 'strategic partnership' with the smaller or core Europe, as institutionalized in the EU, but it always favored the transformative and pluralistic creation of a Greater Europe, in which it would be at its origins a founder and core member. (pp. 4-6)

Cabe anotar que el Ministerio de Relaciones Exteriores ruso suele tomar como hecho un orden tripolar ${ }^{50}$, basado en la primacía de Estados Unidos, China y la propia Rusia — en cambio, la UE es considerada como un importante bloque económico, pero no como un actor político internacional autónomo-; aunque, esta idea no es plenamente recogida por los expertos. El ya citado Karaganov (2016), por ejemplo, parte del escenario de una «bipolaridad suave», construida a partir de Occidente y una «Gran Eurasia»:

The world may be moving towards a new (soft) form of bipolarity. [...] This will be accompanied very likely by the emergence of another center, Greater Eurasia, around the Shanghai Cooperation Organization. China can play a leading economic role in this new center, but its supremacy should and hopefully will be balanced out by other powerful partners such as Russia, India and Iran. (p. 464)

Finalmente, como cuarto objetivo, Rusia busca el reconocimiento de derechos especiales en la Eurasia postsoviética, es decir el espacio que coincide con la ex Unión Soviética, con la excepción de las tres repúblicas bálticas. Al respecto, se suelen usar los términos de «extranjero cercano» о «русский мир» («mundo ruso»), como una zona de influencia donde Moscú procura defender sus intereses de orden geopolí-

\footnotetext{
49 Sobre las lógicas de expansión y transformación, véase Sakwa, 2020 b.

${ }^{50}$ El propio Lavrov, por ejemplo, comentó en el año 2013: "The activity of the Russian diplomacy is directed to making a positive influence on global processes in the interests of formation of a stable, —ideally self-regulatingpolycentric system of international relations, in which Russia rightfully plays a role of one of three key centers» (p. 3).
} 
tico (sobre todo, en las repúblicas en Europa Oriental, como zona amortiguadora), económico (por las reservas y ductos de hidrocarburos) y en materia de seguridad (por la presencia de redes terroristas $\mathrm{u}$ otras expresiones del crimen organizado transnacional). También es una región importante por la presencia de aproximadamente 25 millones de rusos y/o rusófonos. Por otro lado, la posesión de una zona de influencia es considerado como un derecho especial reservado únicamente para las grandes potencias, en línea con la doctrina Monroe para Estados Unidos o en el pasado, Mitteleuropa para Alemania. Como tal, se trata de un elemento que contribuye con el estatus de las grandes potencias, aunque claramente «relativiza» los derechos internacionales para aquellos Estados secundarios y partícipes en sus respectivos órdenes regionales. Allison (2017) describió así la visión rusa sobre el orden global y los órdenes regionales:

An overarching unified global system, it is suggested, coexists with regional public orders, one of which is a regional Russian regional order encompassing much of postSoviet Eurasia. At this regional level, it is argued, the normative content of international law is determined by the dominant state in the subsystem (p. 539).

Pasando a las estrategias internacionales de la Federación Rusa, ante la creciente sensación de inseguridad, Moscú ha vuelto a apostar por la figura de la zona amortiguadora. Esto aplica especialmente en el caso de Ucrania, al constatar la dificultad para incorporarla dentro de su zona de influencia, por ejemplo, a través de la Unión Económica Eurasiática o la Organización del Tratado de Seguridad Colectiva (OTSC). Por ello también, la insistencia rusa en la neutralidad de Kiev, la libertad de lazos económicos entre ambas naciones, así como la federalización del Estado ucraniano, a fin de garantizar los derechos socioculturales y políticos de la minoría rusa/rusófona (tal como queda contemplado en los Acuerdos de Minsk II). En el escenario de la llegada al poder de una nueva generación política más prooccidental en Bielorrusia, el otro Estado estratégicamente ubicado entre la Unión Europea y Rusia, se podría esperar una modalidad de actuación similar a la observada en el caso ucraniano.

Otra manera, más global, de preservar la seguridad nacional consiste en el tradicional «balanceo» frente a Estados Unidos, que con un 38\% del gasto militar global, aún es una "superpotencia militar» - frente a un $14 \%$ y $3,4 \%$ que corresponden a China y Rusia, respectivamente (SIPRI, 2020)—. En este sentido, tanto la cooperación militar y en materia de seguridad con China (y otros Estados), como la intervención rusa en Siria, constituyen ilustraciones de esta estrategia. En el primer caso, la cooperación bilateral y plurilateral (por ejemplo, a través de la Organización de Cooperación de Shanghái) entre Moscú y Beijing ha llegado al grado de semialiados, con base en una convergencia actual de intereses frente a Occidente. Respecto a 
Siria, además de haber logrado neutralizar la amenaza de Daesh en el país, Rusia también bloqueó los intentos de derrocamiento de al-Assad por parte de Occidente, revirtiendo así el equilibrio de poder del Medio Oriente. Evidentemente, el propio aumento en el gasto militar entre los años 2008-2016 — de un 3,1\% a un 5,5\% del PBI (SIPRI 2021) — constituye otra expresión de esta política balanceadora. Cabe anotar que la función como "contrapeso» del sistema internacional ha sido plenamente reconocida por el Estado ruso, tal como lo demuestra el siguiente fragmento del último "Concepto de Política Exterior»: «Russias foreign policy is open and predictable. It is characterized by consistency and continuity and reflects the unique role Russia has played for centuries as a counterbalance in international affairs and the development of global civilization» (MID, 2016, p. 6).

En un orden más sutil, Rusia también ha optado por el balanceo suave (soft balancing) frente a Occidente. En este sentido, el ejercicio del poder de veto en el Consejo de Seguridad de la ONU, sobre todo, en dossiers donde la soberanía estatal queda cuestionada, es conocido. En general, con su priorización del multilateralismo, Rusia, además de fomentar la cooperación de mutuo interés y limitar el uso de la fuerza entre las potencias, también procura forjar alineamientos con potencias emergentes y Estados disconformes con las políticas de Occidente de las últimas tres décadas. Al respecto, es menester resaltar que Moscú defiende, al igual que los emergentes, una perspectiva conservadora del multilateralismo - en palabras de Clunan, un Charter Liberalism - basado en los históricos principios westfalianos y no en valores liberales o lógicas pos soberanas, tal como quedaron expuestos por Occidente luego del fin de la Guerra Fría (Clunan, 2018; Sakwa, 2020a) ${ }^{51}$. También el respaldo ruso a favor de la autonomía estratégica de la Unión Europea, al señalar sus divergencias con Washington, o el acercamiento hacia Turquía, pese a ser integrante de la OTAN, están claramente orientados a debilitar la posición internacional de Estados Unidos. Aunque no estrictamente resulta ser un ejemplo del balanceo suave, el esfuerzo ruso para presentarse como una alternativa civilizacional de Occidente, al defender «valores cristianos» en oposición a un presunto posmodernismo, materialismo y nihilismo, busca contribuir al cuestionamiento de la autoridad de Occidente en el sistema internacional (Robinson, 2020).

Una cuarta estrategia concierne a la estrategia toma y daca, mencionada anteriormente, como una manera de expresar los principios de igualdad y reciprocidad (Trenin, 2015). Además de los ejemplos citados sobre los gasoductos, la reciprocidad de sanciones y el reconocimiento unilateral de Abjasia y Osetia del Sur, resalta

\footnotetext{
51 Algunos autores rusos refieren, de modo peyorativo, al multilateralismo liderado por Estados Unidos como un «unilateralismo colectivo» (Clunan, 2018).
} 
la aspiración rusa por ofrecer una contranarrativa con relación a Occidente en materia de historia, actualidad y política internacional, a través de medios televisivos y sociales, y el propio discurso de sus líderes. En ese afán de neutralizar estos discursos, fuentes occidentales suelen presentar la contranarrativa rusa como noticias falsas (fake news), revisionismos o un aspecto importante de las denominadas «zonas grises», aplicadas por Estados «revisionistas» en su pugna con Occidente. Además de las guerras informativas, también la guerra jurídica (o lawfare), económica y cibernética, así como los intentos de injerencia en la política doméstica para socavar la autoridad del contrincante, son considerados como «zonas grises» al desarrollarse en tiempos de paz formal, aunque «al límite de la legalidad internacional» (Baqués, $2017)^{52}$. No obstante, es evidente que estas prácticas no solo son antiguas (con la propaganda política y la figura de boicots internacionales), sino también activadas por el propio Occidente en aquellos escenarios donde el uso de la fuerza no es deseable. Cabe mencionar que la mayoría de estos casos de "toma y daca» tienen un carácter eminentemente simbólico. En la misma línea, por ejemplo, la visita de un crucero nuclear ruso a Cuba, Nicaragua y Venezuela en 2008, la participación del presidente Medvédev en una cumbre del ALBA en 2009 y el envío de bombarderos estratégicos Tu-160 a Caracas a fines de 2018, han sido interpretados como reacciones, de orden simbólico, a iniciativas de Occidente (Adins y Rooney, 2019).

A fin de obtener su estatus como gran potencia, al igual que las potencias emergentes, Rusia ha realizado una serie de prácticas de alta visibilidad y asociables con la política exterior de un poder establecido. En este sentido, la organización de diversas cumbres internacionales (BRICS en 2009/2015/2020, APEC en 2012 y el G20 en 2013) y megaeventos deportivos (las Olimpiadas de Invierno de 2014 y la Copa Mundial de Fútbol en 2018) tienen que ser comprendidos bajo esta luz. Así también, este entendimiento se hace extensivo, a la presentación frecuente de nuevas armas de última tecnología, su protagonismo en el espacio y, aunque en un contexto muy diferente, la participación rusa en la denominada "diplomacia de vacunas» expuesta en medio de la pandemia de COVID-19.

Finalmente, respecto al «extranjero cercano», en su calidad de «hegemón regional», Rusia moviliza una combinación de zanahorias y garrotes. Por un lado, Moscú actúa como gestor de seguridad regional, por ejemplo, con su mediación en los conflictos en la zona (siendo el último ejemplo, Nagorno Karabaj, a fines de 2020), y con su respaldo a la lucha contra el narcotráfico y grupos yihadistas armados en el Asia

\footnotetext{
52 La RAND Corporation (2019), por ejemplo, define a una zona gris como: «[...] an operational space between peace and war, involving coercive actions to change the status quo below a threshold that, in most cases, would prompt a conventional military response, often by blurring the line between military and nonmilitary actions and the attribution for events».
} 
Central. También en el ámbito económico, sigue siendo el pivote de la región al subvencionar la venta de sus hidrocarburos a las repúblicas exsoviéticas menos desarrolladas, entre otras formas de asistencia económica, y con la aplicación de una política migratoria marcadamente flexible. En contraste, al cruzar las líneas rojas trazadas por Moscú (como ambicionar la adhesión a la OTAN o discriminar a la minoría rusa), han seguido boicots económicos, políticas de visado más estrictas, la suspensión de la exportación de gas, e incluso el uso de la fuerza militar o en el dominio cibernético (por ejemplo, a través de la manipulación cibernética de sistemas de control industrial).

\section{Rusia: ¿una potencia revisionista?}

A la luz del marco teórico y la revisión de los principales hitos, premisas y estrategias de política exterior rusa pos Guerra Fría, se evalúa el grado de revisionismo en la proyección internacional de Moscú. Para ello, se partirá de una distinción entre los ámbitos ideológico, económico, normativo-institucional y territorial, para luego aplicar el enfoque teórico propuesto por Michelle Murray.

En el plano ideológico, especialmente, a partir de la segunda reelección de Putin en el ańo 2012, Rusia se muestra claramente como un actor conservador; en este sentido, una antípoda de la Unión Soviética del siglo pasado. Así lo demuestran, el discurso y las propias políticas públicas del gobierno ruso en respaldo de los valores tradicionales, incluyendo la santidad de la familia —entendida como la unión de hombre y mujer-, el rol indispensable de la religión como factor cohesionador y fuerza espiritual, la centralidad del Estado en la sociedad, así como el patriotismo (Trenin, 2015). Si bien con esta narrativa conservadora, Rusia busca diferenciarse de Occidente — considerado moralmente en declive-, no prioriza la exportación de dichos valores al resto del mundo, tal como sucedió, por ejemplo, con el marxismoleninismo al inicio de la era soviética. Por lo tanto, los alineamientos coyunturales de Moscú con fuerzas políticas consideradas anti-establishment en Occidente, tanto de tendencia derechista (v.g. Front/Rassemblement National, Lega Nord o Alternative für Deutschland) como de la izquierda (Syriza y algunas agrupaciones progresistas en América Latina), han respondido a cálculos geopolíticos y no a algún radicalismo ideológico de Rusia.

Como es sabido, común entre estas fuerzas, se encuentra su rechazo, no solo hacia la hiperglobalización de las últimas décadas, sino también al histórico promotor de estos valores cosmopolitas, Estados Unidos. Por esta misma razón, el optimismo que generó en Rusia la llegada al poder de Donald Trump se explicó más por la promesa del entonces candidato de poner fin a las políticas intervencionistas en otras partes 
del mundo, apostando a su vez por una orientación neoaislacionista y su tono más amigable hacia Moscú en aquellos meses, lo que fue visto como una oportunidad de mejora para las relaciones bilaterales (Sakwa, 2020a). Finalmente, las buenas relaciones con algunos líderes de la izquierda en América Latina (y la propia Europa), durante la década pasada, se construyeron principalmente, a partir del discurso antiimperialista que suele acompañar a la izquierda en la región latinoamericana, más que en alguna similitud ideológica. Cabe anotar que, desde una perspectiva más general, el discurso conservador del Kremlin acompaña la idea de un mundo policéntrico, a la vez pluralista en términos ideacionales —y, por consiguiente, poshegemónico-, como posoccidental.

En lo referente al campo económico, también se suele presentar a Rusia como un actor revisionista. En la práctica, si bien Moscú no juega un rol protagonista en la gobernanza comercial y financiera global, tal como sucede con los emergentes China, India y Brasil; sí suele respaldar los reclamos de estos, al esperar que una reforma de la arquitectura financiera - por ejemplo, con un papel más reducido para el dólar estadounidense- contribuya con la democratización del orden internacional. Por otro lado, tanto su ingreso a la OMC, como su candidatura para acceder a la OCDE - considerada como un organismo principalmente occidental- contradicen una eventual lógica revisionista. Pese a que, a lo largo de los últimos años, el Estado ha vuelto a ocupar un lugar importante en el conjunto de la economía rusa ${ }^{53}$, las élites del país no solo están plenamente conectadas con las redes capitalistas globales, sino que también han obtenido enormes beneficios con la incorporación del país al orden liberal. Para Clunan (2018):

Millions of Russians, including Putin and his powerful supporters, have benefited mightily from Russia's engagement with the global economy and its integration into European markets, not to mention their use of sovereignty-free zones such as offshore financial havens. De-globalization, which some argue began in 2008, puts all this as risk. [...] Russia does not come out the winner in a protectionist world. (p. 54)

Por lo dicho queda claro que Rusia no busca derrocar o desestabilizar el orden económico, por más que, desde una óptica geopolítica, desea mantener a distancia a empresas extranjeras en algunos de los sectores más sensibles.

\footnotetext{
${ }^{53}$ Aunque no se cuenta con cifras oficiales, según Abramov, Radygin y Chernova (2017) y Sakwa (2020c), el gasto estatal consolidado llegó a aproximadamente un 36\% del PBI para el año 2016, de los cuales un 13\% correspondió al pago de las pensiones u otros servicios sociales. Por otro lado, un 30\% de la PEA trabaja para el Estado, tanto a nivel federal, regional y municipal, como en las decenas de empresas públicas (SOE). Respecto a las últimas, el Estado cuenta con una presencia protagónica en sectores considerados estratégicos, como el complejo militar industrial, minería, energía nuclear y ferrovías. Por ello, la economía rusa es considerada como un ejemplo de un «capitalismo gestionado».
} 
De acuerdo con lo sustentado en los acápites anteriores, Rusia tampoco juega un rol subversivo en el terreno normativo-institucional. Al contrario, de las cuatro dimensiones, constituye el escenario donde más se denota el conservadurismo y el carácter reactivo de la política exterior rusa actual. $\mathrm{Al}$ igual que las potencias llamadas emergentes, la prioridad de Rusia en el ámbito internacional refiere a la defensa de la soberanía, considerada como un pilar fundamental para la estabilidad internacional desde la histórica Paz de Westfalia. Por esta razón, ha compartido con estos países un gran escepticismo sobre cómo, a partir de los años noventa, Occidente empezó a reinterpretar las normas básicas de la política internacional desde un espectro liberal radical, pasando por alto el derecho internacional y las decisiones tomadas en el marco del Consejo de Seguridad de la ONU. Las siguientes líneas de Sakwa (2020b) resultan muy aclaradoras sobre el particular:

The original liberal world order after 1945 developed as one of the major pillars (the Soviet Union was the other) within a bipolar system and was initially a relatively modest affair, based on the UN Charter defending the territorial integrity of states (although also committed to anti-colonial national self-determination), multilateral institutions, open markets that was later formulated as the 'four freedoms' of labor, capital, goods and services, accompanied by a prohibition on the use of force except in self-defence. After 1989 the liberal world order, as the only surviving system with genuinely universal aspirations, assumed more ambitious characteristics, including a radical version of globalisation, democracy promotion and regime change». (p. 8)

Precisamente desde este enfoque, el autor británico tilda a Rusia (y China) de Estados neo-revisionistas, al criticar las prácticas de la política internacional pos Guerra Fría liderada por Occidente, mas no las normas sobre las cuales se construyó el orden internacional pos Yalta.

Por otro lado, a nivel institucional, es importante recalcar el liderazgo chino (en otros casos, colectivo) de una serie de nuevos organismos en los que participa Rusia y que son conocidos por sus posturas críticas hacia ciertas políticas de Occidente, tales como, la Organización para la Cooperación de Shanghái, el Banco Asiático para la Inversión en Infraestructura y los BRICS (y su Nuevo Banco de Desarrollo). A su vez, el protagonismo ruso en el regionalismo eurasiático, tanto en su variante económica (con la UEEa), como en su pilar militar (con la Organización del Tratado de Seguridad Colectiva), recién llegaría a despegarse luego del rechazo occidental a los pedidos rusos de crear una nueva arquitectura de seguridad paneuropea y de profundizar sus lazos con la Unión Europea (por ejemplo, a través de los «Cuatro Espacios Comunes»). Por cierto, la gobernanza de las instituciones en ambos niveles (global y regional) evidencia el pragmatismo de Rusia —y, con extensión China—, lo que vuelve a indicar que Moscú no dispone de una alternativa normativa frente a Occidente para gestionar la política internacional. 
Indudablemente, es en el cuarto dominio, el territorial, donde Rusia más se acerca al revisionismo. En efecto, tanto la efímera guerra rusa-georgiana de 2008, como la toma de la Crimea/Sebastopol en 2014 y su posterior accionar en el Donbás, han sido actos a todas luces revisionistas, acaecidos para detener un nuevo avance de la OTAN en el espacio postsoviético. No obstante, cabe tomar nota del hecho que Rusia aún sigue defendiendo la salida «federal» para detener el conflicto en el este de Ucrania, en lugar de incorporar a las denominadas «Repúblicas Populares» de Donetsk y Luhansk. De la misma manera, tampoco ha respondido a la demanda formulada por las autoridades separatistas de Transnistria, Abjasia y Osetia del Sur - $\mathrm{y}$ diversas agrupaciones irredentistas en Rusia - para permitir su ingreso como nuevas unidades de la Federación Rusa. Incluso en el hipotético caso que el Kremlin aspire a reintegrar a la ex Unión Soviética a través de la fuerza, sus élites están conscientes de que carecen de las capacidades económicas necesarias para implementar una política tan riesgosa - sin mencionar el inmenso deterioro de su imagen internacional- . Por otro lado, la cordialidad que une a Moscú con las repúblicas exsoviéticas como Azerbaiyán, Moldavia, Turkmenistán y Uzbekistán — ninguna forma parte del regionalismo eurasiático—, demuestra la posibilidad de una relación equilibrada y mutuamente beneficiosa en el «extranjero cercano», siempre que se mantenga la neutralidad militar. En síntesis, ante la expansión de la OTAN, considerada una línea roja a fin de preservar su seguridad y estatus internacional, Rusia claramente ha violado el derecho internacional y la integridad territorial de dos de sus vecinos; no obstante, estas actuaciones no convierten a Rusia en un actor sistemáticamente revisionista en el escenario regional, ni mucho menos a nivel global.

A partir de las afirmaciones desarrolladas en esta sección, se podría resumir que Rusia no busca imponer alguna ideología al resto del mundo, impulsar una desglobalización en el terreno económico, reemplazar las normas — westfalianas - del orden internacional, ni reconstruir manu militari una «Unión Soviética 2.0». Por lo tanto, queda la interrogante: ¿Por qué en Occidente se suele presentar a Rusia como un actor revisionista y fuente de inestabilidad sistémica?

Para responder esta pregunta, la aplicación del enfoque teórico planteado por Murray (2019) resulta relevante parece alcanzar una respuesta tentativa. Tal como se mencionó en el marco teórico, en sus interacciones constantes con el resto del mundo, un Estado busca reafirmar su identidad. En el caso ruso, esta identidad corresponde a la de una gran potencia, al considerar sus capacidades duras, autonomía política y gran trayectoria en la diplomacia global. En su afán de reforzar dicha identidad, sobre todo desde el año 2012, Moscú ha desplegado varias prácticas de reconocimiento, tales como: mostrar un gran activismo en la política internacional; alinearse con potencias emergentes en grupos de estatus como los BRICS; reafirmar su presencia 
-incluso sin abstenerse de la fuerza - en su zona de influencia, a través de sus actos de toma y daca; así como, tratar de imponer el respeto y la igualdad frente a países occidentales. Estas acciones, empero, en lugar de haber alcanzado el objetivo del reconocimiento por parte del principal «Otro significativo» —Occidentefueron interpretadas como amenazas para sus intereses geopolíticos, activando así un proceso de securitización de la relación con Rusia, que culminó con un clásico dilema de seguridad y la construcción de la narrativa sobre una Rusia revisionista. A su vez, esta falta de reconocimiento sería interpretada por Moscú como una falta de respeto y una repetición de las tradicionales políticas de contención de Occidente en su contra. No obstante, tal como advierte Murray (2019), no es que dichas prácticas de reconocimiento, si hubiesen provenido de otros actores, automáticamente hubieran originado un mismo resultado. Para ello, el grado de similitud u otredad a nivel de identidad política, cultural y hasta económica, parece ser un factor crítico.

$\mathrm{Al}$ respecto, es menester reconocer que, desde su entrada a la sociedad europea de Estados en el siglo XVI, Occidente se ha aproximado a Rusia con una mezcla de desprecio, temor y/o indiferencia. Estas tres actitudes constituyen un ciclo recurrente en la historia que Smith (2019) ha denominado Russia Anxiety. La tendencia, profundamente arraigada en las relaciones internacionales y de origen occidental, suele considerar al país, como bárbaro, oriental (con su típica connotación peyorativa en Occidente), violento, fanático o atrasado, según el contexto. Como tal, el fenómeno precede a la narrativa sobre el peligro rojo, sumamente poderosa durante la era soviética. Además, concierne a una representación sobre el país entero y no solo respecto a sus élites, tal como lo ilustra la siguiente afirmación del ex director de Inteligencia Nacional, John Clapper, en 2017: «Russians are almost genetically driven to coopt, penetrate, gain favor, whatever, which is a typical Russian technique» (citado en Sakwa, 2020b). Por lo tanto, la Russia Anxiety no solo se deriva de lo que Neumann (2007) describe como la «falta de poder social» del Estado ruso a partir del siglo XIX, en referencia a su trayectoria de regímenes despóticos y la relativa ineficacia de su administración pública en comparación con Europa occidental; sino que se trata de un proceso de carácter más histórico y esencialmente irracional. Por otro lado, claramente constituye el producto de un profundo desconocimiento de la realidad rusa actual. Las ideas de que Moscú sigue siendo el bastión de una izquierda subversiva o que, con Putin como presidente, Rusia ha vuelto a ser un régimen totalitario o una «autocracia neo-soviética», así lo demuestran.

Evidentemente, el carácter autoritario del actual gobierno facilita presentar a Rusia —usualmente, en tándem con China— como un «otro» frente a Occidente en la política internacional. No obstante, resulta importante recordar que este mismo Occidente dio su respaldo a Yeltsin durante la campaña electoral presidencial de 
1996, a menos de tres años de que el entonces presidente diera la orden de atacar a la "Casa Blanca» — la entonces sede del parlamento ruso-, a fin de neutralizar la oposición a sus políticas económicas y que dejó un saldo de cientos de víctimas mortales. Por consiguiente, ha sido la búsqueda por mantenerse como un actor independiente en el sistema internacional con intereses propios, uno de los pilares de la desconfianza estructural de Occidente frente a Moscú. Al respecto, las palabras expresadas por Kozyrev, durante su gestión como ministro de Relaciones Exteriores, parecen ser importantes: "When we agree with the West, they consider us a democratic country but when we stand up for our own interests, i.e., do what everyone else does, we are being accused of returning to the past ${ }^{54}$.

«I think it is the beginning of a new Cold War [...] It shows so little understanding of Russian history and Soviet history. Of course, there is going to be a bad reaction from Russia, and then [the NATO expanders] will say that we always told you that is how the Russians are - but this is just wrong» (citado en Friedman, 2 de mayo de 1998). Estas son las palabras de George Kennan, durante una entrevista para The New York Times, luego de la oficialización de la primera ampliación de la OTAN pos Guerra Fría.

Después de veintitrés años, estas declaraciones parecen tener un carácter profético. Efectivamente, Rusia tomaría dicho accionar (y los que siguieron en los años siguientes), como un acto desleal por parte de Occidente e incluso una humillación nacional. Además, terminó siendo un duro golpe para los reformadores en Rusia, aplastando así las esperanzas de quienes creían en la posibilidad de la transformación de la OTAN en una alianza no militar, con Rusia como uno de sus miembros. La sensación de exclusión como un integrante autónomo de Occidente, a su vez, originaría una especie de "síndrome Weimar», al empoderar las voces nacionalistas que no solo presionaron a favor de una proyección internacional más asertiva, sino también más enfocada hacia Oriente. Asimismo, entre otros factores, el aislamiento de los reformistas contribuiría con la consolidación del autoritarismo en la política rusa.

Queda entonces la interrogante: ¿qué perspectivas caben para una relación tan deteriorada? Por un lado, la aprobación de una prórroga por cinco ańos del New START,

\footnotetext{
${ }^{54}$ https://networks.h-net.org/node/28443/discussions/6862976/h-diplo-review-essay-292-kozyrev\%C2\%A0firebird-elusive-fate-russian
} 
como una de las primeras gestiones internacionales de Joe Biden como presidente - pese a las múltiples tensiones en otros dominios-, es de suponer que las dos exsuperpotencias están conscientes del peligro de una securitización de las relaciones entre dos potencias nucleares. Por otro lado, es predecible que una continuada emergencia de China en el sistema internacional durante los próximos ańos bien podría conllevar una mayor convergencia estratégica entre Rusia y Occidente, sobre todo con Europa, tal como ya lo expresó el propio presidente francés ${ }^{5}$. La misma Europa, cada vez más enfrentada con la presión migratoria desde África y los radicalismos religiosos del mundo islámico, y encaminada hacia una mayor autonomía estratégica de Estados Unidos luego del Brexit, también tiene mucho que ganar con una relación más equilibrada con Moscú.

Por otro lado, las repetidas propuestas rusas sobre una "Gran Europa» o un "Gran Occidente» dejan en claro que, pese al discurso eurasiático, Rusia aún se considera más un país de Occidente que de Oriente. Asimismo, la largamente postergada modernización de la economía rusa requiere de inversiones extranjeras que, considerando la existente asimetría con el gigante asiático, necesitarán diversificarse.

Por todos estos factores, una normalización de las relaciones, en el marco de un nuevo orden internacional —realmente- policéntrico, con respeto mutuo por las diferencias políticas y económicas, beneficiaría a ambas partes. En este sentido, la doctrina de coexistencia pacífica, base de la histórica Détente, tal vez debería ser reconsiderada. Evidentemente, al igual que durante la Guerra Fría, no resultará un proceso sencillo. Antes que nada, exigirá una acomodación mutua, un abandono de la lógica securitizadora de los últimos años y, de modo más general, una neutralización de la histórica Russia Anxiety, por parte de Occidente. De no ocurrir esto, una continuación de la situación actual solo generaría un claro ganador: la República Popular China.

\section{Conclusiones}

Sin subestimar las presiones sistémicas o domésticas que puedan estar en la base de la proyección revisionista de un Estado, es menester comprender que se trata de una categoría política, socialmente construida. Asimismo, un Estado puede mostrarse más o menos revisionista —o reformista— en diversos ámbitos o alcance geográfico. Por otro lado, resulta cuestionable la tradicional afirmación que atribuye el revisionismo únicamente a las potencias emergentes. En el caso particular analizado, Rusia constituye una especie de potencia híbrida, que combina algunas de las capacidades y estrategias de las potencias emergentes con aquellas propias de las tradicionales.

55 https://www.france24.com/en/20200215-macron-calls-for-better-long-term-relations-with-russia 
Respecto a los objetivos centrales que sustentan la política exterior de la Rusia posindependencia, resalta la continuidad —y el consenso que ello genera a nivel doméstico- en su afán de obtener el reconocimiento como gran potencia, a partir de sus capacidades actuales y su trayectoria histórica, particularmente, como contribuyente con el final de la Guerra Fría. Como tal, desde los años noventa, Moscú se negó a convertirse en un socio menor de un Occidente ampliado y, en defensa de sus propios intereses, ha ido promoviendo la idea de una Europa y un Occidente transformado, con base en la participación del país como socio igual. Desde esta perspectiva, Rusia no busca destruir el Orden Internacional Liberal, sino obtener un lugar privilegiado —al igual que Estados Unidos o la Unión Europea— en este.

Evidentemente, la toma de Crimea y Sebastopol en el año 2014 y la participación rusa en la guerra híbrida del Donbás, han constituido actos de revisionismo territorial en el denominado «extranjero cercano». Tal como se argumentó, ambas acciones fueron las respuestas rusas ante las constantes presiones de Occidente - a través de la OTAN y, en menor medida, la Unión Europea- en la zona estratégica de Europa Oriental, históricamente un espacio de tránsito entre Rusia y las potencias de Europa Central. Más allá del revisionismo territorial mostrado en Ucrania, en otras aéreas —económico, normativo, institucional e ideológico—, Moscú ha tenido un comportamiento sorprendentemente conservador.

Sin embargo, en Occidente se ha mantenido una lectura distinta de los hechos. Así, por ejemplo, la administración Obama tildaría a Rusia como una potencia regional —más no global—, y en declive —en vez de emergente—. Asimismo, al igual que la República Popular China, el país suele ser presentado como un actor revisionista sistémico que, con una lógica propia del siglo XIX, actúa desafiando el orden internacional basado en reglas. Una respuesta a esta divergencia ha sido formulada, a través de la aplicación de la teoría de Murray (2019). Ante la negativa occidental de otorgarle el estatus de gran potencia — por ejemplo, a través de las propuestas de una "Gran Europa» o un "Gran Occidente» -, Rusia empezó a instaurar varias prácticas de reconocimiento. Al considerar las (históricas) diferencias sociopolíticas y culturales entre Rusia y Occidente —el "otro significativo" de este caso-, este empezó a securitizar dichas acciones, considerándolas como desafiantes hacia sus intereses estratégicos y su propia identidad internacional. Como tal, la histórica Russia Anxiety volvería a interponerse como un obstáculo para ver la plena incorporación rusa al concierto de potencias o, incluso, al propio Occidente. En su lugar, se empezó a construir la narrativa sobre una Rusia como actor revisionista frente al «Orden Internacional Liberal». 


\section{Referencias bibliográficas}

Adins, S. y Rooney, M. (2019). Las relaciones entre el Perú y Rusia. Revisión e interpretación desde las Relaciones Internacionales. KAS/IDEI.

Allison, R. (2017). Russia and the post-2014 international legal order: revisionism and realpolitik. International Affairs, 93(3), 519-543.

Carr, E. H. The Twenty Years' Crisis 1919-1939. An Introduction to the Study of International Relations. The Macmillan Press Ltd.

Contessi, N. (2017). Prospects for the accomodation of a resurgent Russia. En T.V. Paul (Ed.), Accomodating Rising Powers. Past, Present, and Future (pp. 268-290). Cambridge University Press.

Cooley, A., Nexon, D. y Ward, S. (2019). Revising order or challenging the balance of military power? An alternative typology of revisionist and status-quo states. Review of International Studies, 45(4), 689-708.

Copeland, D. (2000). The Origins of Major War. Cornell University Press.

Clunan, A. (2018). Russia and the Liberal World Order. Ethics and International Affairs, $32(1), 45-59$.

Davidson, J. (2006). The Origins of Revisionist and Status-quo States. Palgrave Macmillan.

Feklyunina, V. (2019). Russian Foreign Policy. En R. Sakwa, H. Hale y S. White (Ed.), Developments in Russian Politics 9 (pp. 165-179). Duke University Press.

Friedman, T. (2 de mayo de 1998). Foreign Affairs; Now a Word from X. The New York Times. https:/www.nytimes.com/1998/05/02/opinion/foreign-affairs-now-a-word-from-x. html

Gilpin, R. (1981). War and Change in World Politics. Cambridge University Press.

Ikenberry, J. (2002). America’s Imperial Ambition. Foreign Affairs, 81(5), 44-60.

Ikenberry, J. (2017). The plot against American foreign policy. Foreign Affairs, 96(3), 2-9.

Istomin, I. (2021). Institutional Revisionism in International Politics: The Product of Rising, the Child of Decline or Something Else? Valdai Discussion Club Report. https://valdaiclub.com/a/reports/institutional-revisionism-in-international/

Kaczmarski, M. (2020). Russia and China in Global Governance. En E. Parlar Daly E. Erşen (Eds.), Russia in the Changing International System (pp. 95-111). Palgrave Macmillan.

Karaganov, S. (2014). Europe and Russia: preventing a New Cold War. Russia in Global Affairs. https://eng.globalaffairs.ru/articles/europe-and-russia-preventing-a-new-cold-war/

Karaganov, S. (2016). Global Challenges and Russia's Foreign Policy. Russia in Global Affairs. https://eng.globalaffairs.ru/articles/global-challenges-and-russias-foreign-policy/

Kissinger, H. (1966). Domestic Structure and Foreign Policy. Daedalus, 95(2), 503-529.

Kozyrev, A. (1994). The Lagging Partnership. Foreign Affairs, 73(3), 59-71.

Krastev, I. (3 de marzo de 2014). Russian revisionism. Foreign Affairs. https://www.foreignaffairs.com/articles/russia-fsu/2014-03-03/russian-revisionism

Kubyshkin, A. y Sergunin, A. (2012). The Problem of the «Special Path» in Russian Foreign Policy. Russian Politics and Law, 50(6), 7-18. 
Larson, D. y Shevchenko, A. (2014). Russia says no: Power, status, and emotions in foreign policy. Communist and post-Communist Studies, (47), 269-279.

Malinova, O. (2014). Obsession with status and ressentiment: Historical backgrounds of the Russian discursive identity construction. Communist and post-Communist Studies, (47), 291-303.

Mearsheimer, J. (2014). Why the Ukraine Crisis is the West's Fault. Foreign Affairs, 93(5), 77-89.

Morgenthau, H.J. (1948). Politics among Nations. The Struggle for Power and Peace. Alfred A. Knopf.

Murray, M. (2019). The Struggle for Recognition in International Relations. Oxford University Press.

Neumann, I. (2008). Russia as a great power, 1815-2007. Journal of International Relations and Development, 11, 128-151.

Organski, A. (1968). World Politics. Alfred A. Knopf Inc.

Owen, D. (2017). Russia and the West: a roadmap to cooperation through foreign policy linkage of Middle East and Eastern Europe. Вестник МГИМО-Университета, 6(57), 116-131.

Parlar Dal, E. y Erşen, E. (2020). Russia and the Changing International System: An Introduction. En E. Parlar Dal y E. Erşen (Eds.), Russia in the Changing International System (pp. 1-16). Palgrave Macmillan.

Pisciotta, B. (2020). Russian revisionism in the Putin era: an overview of post-communist military interventions in Georgia, Ukraine, and Syria. Rivista Italiana di Scienza Politica, (50), 97-106.

Putin, V. (2007). Putin's famous Munich speech 2007. https://www.youtube.com/ watch?v=hQ58Yv6kP44

RAND Corporation (2019). Gaining Competitive Advantage in the Grey Zone. RAND. https://www.rand.org/content/dam/rand/pubs/ research_reports/RR2900/RR2942/ RAND_RR2942.pdf

Robinson, P. (2020). Russia’s Emergence as an International Conservative Power. Russian Conservatism: An Ideology of a Natural Attitude? Russia in Global Affairs. https:// eng.globalaffairs.ru/articles/russias-conservative-power/

Rosefielde, S. (2001). Premature Deaths: Russia's Radical Economic Transition in Soviet Perspective. Europe-Asia Studies, 53(8), 1159-1176.

Sakwa, R. (2020a). Stasis and Change: Russia and the Emergence of an Anti-hegemonic World Order. En E. Parlar Dal y E. Erşen (Eds.), Russia in the Changing International System (pp. 17-38). Palgrave Macmillan.

Sakwa, R. (2020b). Greater Russia: Is Moscow out to subvert the West? International Politics, (58), 334-362. https://doi.org/10.1057/s41311-020-00258-0

Sakwa, R. (2020c). The Putin Paradox. IB Tauris. 
Sergunin, A. (2020). Russia’s Strategies Towards BRICS: Theory and Practice. En E. Parlar Dal y E. Erşen (Eds.), Russia in the Changing International System (pp. 133-153). Palgrave Macmillan.

Shakleina, T. (2013). Russia in the New Distribution of Power. En V. Nadkarni y N. Noonan. Emerging Powers in a Comparative Perspective. The Political and Economic Rise of the BRIC Countries (pp. 163-182). Bloomsbury.

Schweller, R. (1994). Bandwagoning for profit: Bringing the revisionist state back in. International Security, 19(1), 72-107.

Schweller, R. (2015). Rising Powers and Revisionism in Emerging International Orders. Valdai Papers, 16. https://valdaiclub.com/files/11391/

Smith, M. (2019). The Russia Anxiety. And How History Can Resolve It. Cambridge University Press.

The Guardian. (24 de mayo de 2002). Text: Bush and Putin's joint declaration. https://www. theguardian.com/world/2002/may/24/usa.russia

The White House. (2017). National Security Strategy of the United States of America. https://trumpwhitehouse.archives.gov/wp-content/uploads/2017/12/ NSS-Final-12-18-2017-0905.pdf

Trenin, D. (2015). Russian Foreign Policy as Exercise in Nation Building. En D. Cadier y M. Ligh. Russia's Foreign Policy. Ideas, Domestic Politics and External Relations (pp. 30-41). Palgrave Macmillan.

Tsygankov, A. (2012). Russia and the West from Alexander to Putin. Cambridge University Press.

Ward, S. (2013). Race, Status, and Japanese Revisionism in the Early 1930s. Security Studies, 22, 607-639.

Wolfers, A. (1962). Discord and Collaboration. Essays on International Politics. The Johns Hopkins Press.

Fecha de recepción: 24 de abril de 2021

Fecha de aprobación: 24 de agosto de 2021 